\title{
A high temperature mechanical study on PH 13-8 Mo maraging steel
}

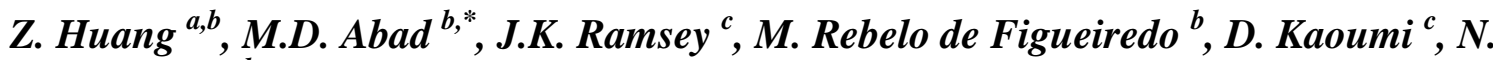 \\ Li $^{a}$, M. Asta ${ }^{d}$, N. Gronbech-Jensen ${ }^{e}$, P. Hosemann ${ }^{a}$ \\ a Xiamen University, College of Energy and School of Energy Research, Fujian, China \\ $b$ University of California Berkeley, Nuclear Engineering, CA, USA \\ c University of South Carolina, Nuclear Engineering, SC, USA \\ $d$ University of California Berkeley, Material Science and Engineering, CA, USA \\ e Department of Mechanical and Aeronautical Engineering, University of California, Davis, CA 95616
}

*Corresponding Author

Dr. Manuel D. Abad

Manueld.abad@berkeley.edu

\begin{abstract}
High temperature mechanical measurements were conducted to study the effect of the dynamic precipitation process of $\mathrm{PH} 13-8$ Mo maraging steel. Yield stress, ultimate tensile strength, total elongation, hardness, strain rate sensitivity and activation volume were evaluated as a function of the temperature. The dynamic changes in the mechanical properties at different temperatures were evaluated and a balance between precipitation hardening and annealed softening is discussed. A comparison between hardness and yield stress and ultimate tensile strength over a temperature range from 300 to $600{ }^{\circ} \mathrm{C}$ is made. The behavior of the strain rate sensitivity was correlated with the intermetallic precipitates formed during the experiments.
\end{abstract}

\section{Keywords}

Mechanical characterization; nanoindentation; martensite; aging; hardening; precipitation. 


\section{Introduction}

Maraging steels have been used in the past for a variety of different applications such as aerospace applications, tools, bearings, medical and dental equipment [1-3]. High temperature precipitation hardening of steels leads to the formation of different precipitate structures in the temperature range from 400 to $600{ }^{\circ} \mathrm{C}$, which have been studied previously on an assortment of different alloys [3-6]. PH 13-8 steel has had a special interest among the many maraging steels due to the controlled precipitation of $\beta$-NiAl precipitates [4-6]. Precipitation hardening on $\mathrm{PH}$ 13-8 has been previously studied by atom probe tomography (APT), transmission electron microscopy (TEM), x-ray diffraction (XRD), Vickers hardness and tensile tests [4,7-11]. In addition, different surface treatments have also been studied on this steel such as plasma nitriding [3,12] and carburing [12], and recently under ion irradiation [13]. However, the mechanical properties at high temperature have not been investigated yet.

Nanoindentation at high temperature (HT) has been used for the last ten years and it has become a powerful technique to measure the mechanical properties at high temperatures such as hardness $(\mathrm{H})$ and reduced modulus on a variety of different materials up to 700 and $750{ }^{\circ} \mathrm{C}$ $[14,15]$, but also other mechanical properties such as strain rate sensitivity (SRS or $m$-value) and activation volume $\left(V^{*}\right)$ [16-19]. In recent studies, the latter properties have been used to study the governing mechanism of deformation by different nanoindentation methods, such as strain rate jump, constant strain rate or constant load [16-18,20].

This investigation focuses on the mechanical properties at high temperature of PH 13-8 steel by nanoindentation and tensile tests. Using nanoindentation, the hardness, strain rate sensitivity and the activation volume have been measured up to $625^{\circ} \mathrm{C}$. Moreover, the yield and ultimate tensile strength and tensile elongation have been studied by high temperature tensile tests up to $800{ }^{\circ} \mathrm{C}$. The aim of conducting both kinds of mechanical tests at high temperature (tensile testing and nanoindentation) is to find a correlation between the testing techniques and the precipitation hardening process. 


\section{Experimental procedure}

\subsection{Material and microstructural characterization}

The chemical composition of PH 13-8 Mo maraging steel, also known under the brand name "Corrax" from Bohler-Uddeholm Corp, Austria is shown in Table I [21]. The as-received material was in the solution-annealed state, after a heat treatment at $850{ }^{\circ} \mathrm{C}$ for 30 min and subsequent air-cooling to room temperature (RT). This resulted in a hardness of $34 \mathrm{HRC}$. The material was sliced into 0.4 " $\times 0.24$ " $\times 0.08$ " plates and then polished with the last step of $0.1 \mu \mathrm{m}$ diamond. The chemical products used for the etching solutions were: $\mathrm{HCl}(122 \mathrm{ml})$, $\mathrm{HNO}_{3}(6 \mathrm{ml})$, Ethanol $(122 \mathrm{ml}), \mathrm{FeCl}_{3}(8.5 \mathrm{~g})$ and $\mathrm{CuCl}_{2}(2.4 \mathrm{~g})$, for $240 \mathrm{~s}$. XRD measurement was made using $\mathrm{Cu} \mathrm{K \alpha}$ (1.54 Angstrom) radiation in a Bruker Advance D8 diffractometer working at $40 \mathrm{~mA}$ and $40 \mathrm{kV}$ and with a step size of $0.02^{\circ} \theta$.

\subsection{High temperature nanoindentation procedure}

The prepared specimens were mounted on an indentation hot stage with high temperature cement (Omega-bond 700, Omega Engineering Inc., Stamford, USA) to subsequently perform nanoindentation and indentation creep testing at different temperatures using a Micro Materials Nanotest Platform 3 (MicroMaterials Inc, Wrexham, UK) instrument. The nanoindenter used for this study is located inside an environmental chamber, which allows purging with different gases to establish a protective atmosphere during the experiments. The chamber was purged and backfilled first with $\mathrm{Ar}$ and subsequently with an $\mathrm{Ar} \pm 5 \% \mathrm{H}_{2}$ mixture gas. The oxygen content inside the chamber was monitored using a QRAE II gas sensor. The oxygen levels were kept between 0 and $1 \%$ while indenting. During the actual nanoindentation test, the gas purging was temporarily suspended to avoid any noise or thermal drift disturbance in the measurements. The indentation measurements were performed with a dwell time of 5 seconds while indentation creep was conducted with a dwell time of 200 seconds at the maximum load. For each target temperature the heating rate was set to $1.6^{\circ} \mathrm{C} / \mathrm{min}$ with a thermalization period of 1 hour per each $100{ }^{\circ} \mathrm{C}$ above RT, following the procedure described by Everitt et al. to get an isothermal contact between the indenter and the surface [22]. The distance between tip and sample during heating was set to $20 \mu \mathrm{m}$ since this provides enough distance to account for expected thermal expansion during heating as well as it is close enough to allow for temperature equalization between tip and sample. After each indent in the maraging steel, a thermal drift assessment was 
carried out. For this procedure the tip was unloaded to $10 \%$ of the maximum load applied and held for 60 seconds while the displacement was recorded. This procedure allowed us to observe that the average drift rate did not exceed $0.20 \mathrm{~nm} / \mathrm{s}$.

For this study, a cubic boron nitride (c-BN) Berkovich indenter was utilized due to its chemical stability at temperatures above $400{ }^{\circ} \mathrm{C}$ [23]. Nanoindentation measurements at different depths on fused silica were carried out prior to the experiments on the maraging steel in order to obtain an appropriate area function, which describes the tip geometry. The hardness as a function of temperature obtained from the nanoindentation experiments was calculated following the Oliver \& Pharr method [24]. The distance between individual indents was greater than $25 \mu \mathrm{m}$ to avoid any influence from neighboring indents. The penetration depth resulting from the constant load of $25 \mathrm{mN}$ varied between $300-500 \mathrm{~nm}$ depending on the temperature. These rather large indents are assumed to sample a representative volume of all present phases in the material (martensite, precipitates and reverted austenite). Three temperature cycles labeled as T1, T2 and T3 (see Table II) were carried out. For the cycles T1 and T3 as-received samples were used, while for cycle T2 the sample after T1 cycle was tested. The detailed heating procedures are shown in Fig. 1a. Details about the test parameters are listed in Table II.

\subsection{High temperature tensile tests}

High temperature tensile samples were prepared, utilizing Electric Discharge Machining. The sample geometry is shown in Fig. 1b. The hot tensile tests were performed using an Instron machine with an integrated furnace in high purity air. Tensile tests were conducted from $100{ }^{\circ} \mathrm{C}$ to $700{ }^{\circ} \mathrm{C}$ at strain rates of $10^{-3} / \mathrm{s}$. The samples were held at the testing temperature for $30 \mathrm{~min}$ before beginning the tensile test and were then taken to fracture. Additionally, 2 pieces of samples were held at 500 and $550{ }^{\circ} \mathrm{C}$ for 4 hours before the test. To determine the yield stress, a $0.2 \%$ offset was used and the ultimate tensile strength was taken from the maximum stress on the flow curve. 


\section{Results}

\subsection{Microstructural characterization of the original sample.}

The original as-received steel has been first studied by optical microscopy and XRD. An $\mathrm{OM}$ image of the original steel is shown in Fig. 2a. Similar microstructure has been shown by Bruhl et al. [12]. The XRD diffractogram from the original steel is plotted in Fig. 2b. The peak with the highest intensity at 44.5 is attributed to the diffraction of (011) of the bcc phase. The main peaks identified are associated with the reflection of the bcc phase (011), (002) and (112). Similar diffractograms could be seen in untreated Corrax in $[3,12]$. A small diffraction associated with the fcc phase (111) could be found. The lattice constant of the bcc lattice has been calculated and it is $0.2871 \AA$. The intensity of the bcc (011) and the fcc (111) reflections were used to estimate the fraction of retained austenite in the alloy. Less than $2 \%$ of retained austenite is found in the as-received sample, in good agreement with the finding by Höring et al. and Schnitzer et al. before aging [4,25].

\subsection{Nanoindentation hardness study at elevated temperatures}

A description of the creep nanohardness test conditions was shown in Section 2.2. Fig. 3a shows a representative load-time curve for a test carried out at $525^{\circ} \mathrm{C}$. As it can be seen, a load of $15 \mathrm{mN}$ was applied for 200 seconds in order to study the creep of the samples at high temperature. Fig. 3b shows representative load-displacement curves obtained at different temperatures during $\mathrm{T} 1$ cycle. The curves obtained at 25 and $300{ }^{\circ} \mathrm{C}$ are very similar, however, a big difference could be seen starting at $400{ }^{\circ} \mathrm{C}$. Observing the part of the graph with load constant we can see easily the significant differences of the creeping behavior at different temperatures. It looks like the curves do not show an extensive creep at RT or $300{ }^{\circ} \mathrm{C}$. However, the creep tends to increase with the temperature over $400{ }^{\circ} \mathrm{C}$. The differences in the creep will be further explained in the text in Section 3.3.

The hardness values obtained from the nanoindentation measurements during the temperature cycles T1, T2 and T3 over temperature are presented in Table II and plotted in Fig. $4 \mathrm{a}, 4 \mathrm{~b}$ and 4c, respectively. Moreover, the hardness of the samples at RT after the HT nanoindentation are plotted with open symbols. For the cycle T1 (Fig. 4a), an increase in hardness can be observed from 4.2 GPa at RT, to $4.6 \mathrm{GPa}$ at $300{ }^{\circ} \mathrm{C}$ and $4.4 \mathrm{GPa}$ at $400{ }^{\circ} \mathrm{C}$. After $400{ }^{\circ} \mathrm{C}$ the hardness decreased rapidly to 3.3 and $3.0 \mathrm{GPa}$ at 500 and $525{ }^{\circ} \mathrm{C}$ respectively. Fig. $4 \mathrm{~b}$ 
displays the hardness of the same specimen during the heat treatment cycle T2 starting from RT. In this case no initial plateau was observed up to $400{ }^{\circ} \mathrm{C}$ but the hardness decreases constantly with temperature. The hardness measured after the $600{ }^{\circ} \mathrm{C}$ heat treatment is found to be lower than the previously measured $(4.8 \mathrm{GPa})$. The temperature cycle T3 also starts with the solutionannealed sample, like T1, and the data is shown in Fig. 4c. A slight increase in hardness was observed between the temperatures of 300 to $450{ }^{\circ} \mathrm{C}$, followed by a decrease at the 550 and 625 ${ }^{\circ} \mathrm{C}$, which is in good agreement with $\mathrm{T} 1$ heat treatment. At the end of heating cycle $\mathrm{T} 3$ the material shows a RT hardness of $4.6 \mathrm{GPa}$. In Fig. 4d, the hardness of the as-received sample and the values of the hardness after each thermal treatment are plotted together with their maximum reached temperature for each cycle. The Vickers hardness (HV) has been calculated following the ratio found by Fischer-Cripps [26,27] in Eq. 1:

$$
H V=0.0945 \cdot H_{\text {Berk }} \quad(\text { Eq. 1) }
$$

As can be seen, there is an increase of the hardness after each thermal treatment, when comparing with the as-received value. The maximum reachable hardness can be found after the thermal cycle T1, which is in good agreement with the literature where the temperature for reaching the maximum hardness is about $525{ }^{\circ} \mathrm{C}$ [5,21]. Höring et al. [7] found $\mathrm{HV}$ values of 365 and $578 \mathrm{Kg} / \mathrm{mm}^{2}$ for the as-received sample and after 3 hours thermal treatment up to 525 ${ }^{\circ} \mathrm{C}$, in good agreement with the values obtained for the as-received sample and after the temperature cycle T1 (378 and $590 \mathrm{Kg} / \mathrm{mm}^{2}$, respectively). Hardness measurements and uniaxial tensile tests carried out by Seetharaman et al. indicated that peak hardening occurred at about $525{ }^{\circ} \mathrm{C}$ due to the apparition of uniformly distributed spherical NiAl precipitates [9]. After cooling the sample to room temperature, the samples exposed to T2 and T3 heating profile show similar hardness values. This can be explained by the fact that both tests were carried out to similar temperatures (600 and $625^{\circ} \mathrm{C}$, respectively). However, it is noticeable the decrease of the hardness after $\mathrm{T} 2$, because the original $\mathrm{H}$ value was relatively $50 \%$ higher than the original hardness value of the as-received sample for T3. Seetharaman et al. also found that tempering at temperatures higher than $525{ }^{\circ} \mathrm{C}$, results in the formation of significant amounts of reverted austenite [9]. However, it should be noted that due to the different size scales of particular features, i.e. precipitates in several nanometers and reverted austenite in hundred nanometers (Schnitzer et al [4]) at most, the nanoindents placed in the material have a lateral dimension of in micrometer scale which leads to the fact that with an indent all present phases are sampled. 


\subsection{High temperature nanoindentation creep}

High temperature indentation creep tests were conducted following the same experimental procedure as reported in $[17,18,20]$. The average strain of 6-10 measurements $v s$. dwell time is plotted in Fig. 5a, 5b and 5c and in Table II. Attending Fig. 5a, it can be seen that in general there is an increase of the strain with the dwell time and temperature. It is noticeable that at 300 ${ }^{\circ} \mathrm{C}$ there is almost no change with the dwell time. The same behavior is observed in $\mathrm{T} 2$ and $\mathrm{T} 3$ curves in Fig. $5 \mathrm{~b}$ and $5 \mathrm{c}$ respectively. In this former test $\mathrm{T} 3$, the test carried out at $350{ }^{\circ} \mathrm{C}$ also does not shown a big increase with the dwell time. It seems like up to $400{ }^{\circ} \mathrm{C}$ the sample experiences little creep. Similar curves were shown by Huang et al. in an ODS material PM2000, where little strain was found up to $120 \mathrm{~s} \mathrm{dwell} \mathrm{time} \mathrm{at} \mathrm{temperatures} \mathrm{below} 500{ }^{\circ} \mathrm{C}$ [19]. The final strain at the end of the dwell time has been plotted in Fig. $5 \mathrm{~d}$. T1 and T2 values has been plotted with the same color because both tests were carried out in the as-received sample, just at different temperatures. As seen in the creep curves, there is an increase of the creep with the temperature and the strain is below 0.2 up to $400{ }^{\circ} \mathrm{C}$. After $450{ }^{\circ} \mathrm{C}$ a big increase in strain is found for $\mathrm{T} 1, \mathrm{~T} 3$, and $\mathrm{T} 2$. It is interesting to note that the strain measured at in $\mathrm{T} 2$ is slightly lower than $\mathrm{T} 1+\mathrm{T} 3$ around $600{ }^{\circ} \mathrm{C}$.

In order to better quantify the data and allow data processing an empirical equation (Eq. 2) is introduced and used to fit displacement-time curves of the creep test so the data can be evaluated further

$$
\Delta h=A \cdot(t-B)^{C}+D \cdot t
$$

Hence the strain rate $\varepsilon$ ' can be expressed with Eq. 3 which has been applied in $[19,28,29]$

$$
\varepsilon^{\prime}=\frac{\Delta h^{\prime}}{h_{0}}=A \cdot C \cdot(t-B)^{C-1}+D
$$

Where $A, B, C, D$ are fitting parameters and $t$ is time. Simultaneously, the displacement regime, namely as the steady-state creep stage, was used for further calculation and discussion. The SRS value $m$ was calculated from the data obtained during the experiments using Eq. 4.

$$
m=\frac{\partial L n H}{\partial L n \varepsilon I}
$$

In addition, the activation volume $V^{*}$, that describes the volume that collectively takes part in the underlying deformation process, was evaluated by Eq. 5, as previously used in [16-19].

$$
V^{*}=3 \sqrt{3} k T\left(\frac{\partial L n \varepsilon^{\prime}}{\partial H}\right)=\frac{3 \sqrt{3} k T}{m H}
$$


In Eq. 4 and 5, $\mathrm{H}$ is the hardness at elevated temperature, $k$ is the Boltzmann constant and $\mathrm{T}$ is the temperature. The activation volume $V^{*}$ is expressed in units of $b^{3}$ where $b$ is the Burger's vector. The lattice constant for a similar material was reported by Höring et al. as $0.2874 \mathrm{~nm}$ [7], therefore $\mathrm{b}$ can be derived as $0.2485 \mathrm{~nm}$ for the (110) and [111] slip system. Table II shows the $m$ and $V^{*}$ values found for the different temperatures. Fig. 6a and $6 \mathrm{~b}$ show the $m$ value and $V^{*}$ as a function of the temperature for $\mathrm{T} 1+\mathrm{T} 3$ and $\mathrm{T} 2$. Attending Fig. 6a, an increasing of $m$ is observed with the temperature for $\mathrm{T} 1+\mathrm{T} 3$ and for $\mathrm{T} 2$. The major change is observed around 400 ${ }^{\circ} \mathrm{C}$, where a big jump on the $m$ is clearly seen. It appears that $m$ reaches a maximum value around 0.350 at $550{ }^{\circ} \mathrm{C}$, and after that point, a small decrease is observed. Again, we observed a small difference between the values from $\mathrm{T} 1+\mathrm{T} 3$ and $\mathrm{T} 2$ at $600{ }^{\circ} \mathrm{C}$, as seen in the strain at the end of the creep (Fig. 5d). A similar decrease has been observed by Primorac et al. in CuNb alloys after testing at $400{ }^{\circ} \mathrm{C}[18]$.

The activation volume, shown in Fig. $6 \mathrm{~b}$, did not change with the temperature up to $500{ }^{\circ} \mathrm{C}$. After that temperature, a continuous increase is found up to values of around $22 \mathrm{~b}^{3}$ for the tests at $625{ }^{\circ} \mathrm{C}$. It is believed, that at temperatures above $550{ }^{\circ} \mathrm{C}$, the sample has been over-aged. Two supposition could explain such a notable increment in $V^{*}$ : the precipitates that were formed below the $525{ }^{\circ} \mathrm{C}$ coarsen and a possible reverse austenite phase apparition.

\subsection{High temperature tensile tests}

The yield stress, ultimate tensile strength and total elongation (TE) obtained from the tensile tests over temperatures from 100 to $700{ }^{\circ} \mathrm{C}$ are presented in Fig. 7a, $7 \mathrm{~b}$ and $7 \mathrm{c}$ respectively, and in Table III. The YS of this material at $100{ }^{\circ} \mathrm{C}$ is $751 \mathrm{MPa}$, and it is slightly lower than the reported value of $817 \mathrm{MPa}$ at RT [8]. An apparent decrease of YS at $200{ }^{\circ} \mathrm{C}$ is shown. Results at 300 and $400{ }^{\circ} \mathrm{C}$ show a small increase with temperature. The maximum YS is found at $500{ }^{\circ} \mathrm{C}$ (758.8 MPa), after that point, a decrease to $637.5 \mathrm{MPa}$ at $550{ }^{\circ} \mathrm{C}, 312.2 \mathrm{MPa}$ at $600{ }^{\circ} \mathrm{C}$ and 161.5 $\mathrm{MPa}$ at $700{ }^{\circ} \mathrm{C}$ are found. A 4 hour-hold time $(240 \mathrm{~min})$ on the specimen brings the maximum YS to $780.5 \mathrm{MPa}$ at $525{ }^{\circ} \mathrm{C}$ and a close result of $777 \mathrm{MPa}$ at $500{ }^{\circ} \mathrm{C}$. However, 4 hour-hold at $550{ }^{\circ} \mathrm{C}$ leads to a $527.7 \mathrm{MPa}$ which represents a YS loss of $150 \mathrm{MPa}$. The YS start decreasing rapidly after the maximum reached at $500-525{ }^{\circ} \mathrm{C}$.

As for the UTS in Fig. 7b, a plateau can be observed up to $300{ }^{\circ} \mathrm{C}$ for the 30 minute-hold specimens. In this case maximum UTS of $1043.6 \mathrm{MPa}$ is achieved at $400{ }^{\circ} \mathrm{C}$. The UTS above 
$400{ }^{\circ} \mathrm{C}$ shows a significant decrease with increasing temperature. It has to be noted that UTS of the 4 hour-hold specimen at $500{ }^{\circ} \mathrm{C}$ shows a $70 \mathrm{MPa}$ drop comparing with 30 minute-hold one, and a similar loss of $62 \mathrm{MPa}$ was observed for the 4 hour-hold specimens at $550{ }^{\circ} \mathrm{C}$. This decrease of the UTS at 500 and $550{ }^{\circ} \mathrm{C}$ is slightly different from the decrease in the YS, because at $500{ }^{\circ} \mathrm{C}$ the YS did not change with the hold time, but at $550{ }^{\circ} \mathrm{C}$, the measured YS showed a significant decrease. It looks like the YS is more affected by the holding time when the tensile tests are carried in the $500-600{ }^{\circ} \mathrm{C}$ temperature range.

If we analyze the TE in Fig. 7c, we do not observe significant differences from $100{ }^{\circ} \mathrm{C}$ to $400{ }^{\circ} \mathrm{C}$ (between 4.1 and $10 \%$ ). At $500{ }^{\circ} \mathrm{C}$ the TE starts increasing up to $45.2 \%$ at $600{ }^{\circ} \mathrm{C}$. At 700 ${ }^{\circ} \mathrm{C}$, a decrease is observed up to $33.8 \%$. No noteworthy differences are found between the samples tested with 30 minute or 4 hour-hold time.

\section{Discussion}

\subsection{Mechanical property evolution at elevated temperatures}

Maraging steels derive their strength from precipitated intermetallic phases, known as $\beta$ $\mathrm{NiAl}$, while these steels can also contain small amounts of austenite. This austenite fraction could result from an uncompleted transformation of austenite into martensite during quenching from solution annealing temperature (retained austenite) of from partial reversion of martensite into austenite during aging (reverted austenite) [8]. Both processes (precipitation and austenite formation) are thermally activated and therefore understanding the effect of thermal activation on the mechanical properties is of value in order to understand the materials performance in a non-room temperature environment. The selected test material reveals a fully developed precipitation structure and a peak hardness after two hours of aging at $525^{\circ} \mathrm{C}$ [21]. Schnitzer $e t$ al. [4] reported a loss of strength due to the high volume fraction (> 8\%) of reverted austenite caused by over-aging in similar materials. However, in Ref [7] it was found that at temperatures below $600{ }^{\circ} \mathrm{C}$ only $1-2 \%$ reverted austenite can be seen due to the short aging time. Thus, it is reasonable to indicate that property changes occur mostly due to precipitation formation and matrix softening.

In this research, the hardness from the solution-annealed state does not change until a temperature of $450{ }^{\circ} \mathrm{C}$, UTS shows a decrease at $500{ }^{\circ} \mathrm{C}$, but the YS remains stable up to $525{ }^{\circ} \mathrm{C}$. Interestingly the YS is reduced at $200{ }^{\circ} \mathrm{C}$ but increases gain up to temperatures of $525{ }^{\circ} \mathrm{C}$. The 
reason for this slight decrease in YS is not known but we can speculate that some of the quench induced microstructural features anneal at these temperatures while some early stage precipice nucleus may form at temperatures up to $525{ }^{\circ} \mathrm{C}$ being responsible for the strength increase. At temperatures above $525^{\circ} \mathrm{C}$, a noticeable decrease in high temperature mechanical properties is observed. It is noted that this material does not decrease its YS or UTS up to $525{ }^{\circ} \mathrm{C}$ being more stable than other martensitic steels [30,31], or even ODS materials [19], which do experience continuous softening in that temperature range. It appears that the matrix strength follows from a careful balance between matrix softening and precipitate strengthening, because in this material no softening and even a slight strengthening is observed up to $450{ }^{\circ} \mathrm{C}$. The precipitate strengthening has been previously studied from 450 to $600{ }^{\circ} \mathrm{C}$ by APT, and recently, it has been demonstrated at RT that under ion beam irradiation precipitate precursors can be formed [13]. No studies have shown the formation of $\beta$-NiAl precipitates below the $450{ }^{\circ} \mathrm{C}$. Although no APT analysis is carried out here, it is reasonable to consider that even at temperatures below the peak hardening temperature, precipitation precursors not easily detectable by APT or TEM might form contributing to the high temperature mechanical property plateau and compensating the decrease in strength caused by matrix softening. Consequently, the balance between the precipitation hardening and the matrix softening at HT is quite stable up to $400{ }^{\circ} \mathrm{C}$. This consideration is supported by the hardness $v s$. temperature test $\mathrm{T} 2$ where the material is fully hardened and continuously loses hardness over temperature without experiencing this plateau as it is observed in the solution-annealed case. At temperatures above $400{ }^{\circ} \mathrm{C}$, a decrease in the properties is observed despite the fact that the precipitates have developed. Therefore, above the $400{ }^{\circ} \mathrm{C}$ it can be stated that the materials softening is more pronounced than the precipitate hardening effect.

The $\mathrm{H}$ values obtained at high temperature nanoindentation have been compared with other steels measured by similar methods. Reichardt et al. [32] showed a decrease on the hardness from 2.8 to $1.8 \mathrm{GPa}$ in an $304 \mathrm{SS}$, and Huang et al. [19] a decrease from 3.82 to $3.80 \mathrm{GPa}$ at 300 ${ }^{\circ} \mathrm{C}, 1.41 \mathrm{GPa}$ at $500{ }^{\circ} \mathrm{C}$ and $1.43 \mathrm{GPa}$ at $600{ }^{\circ} \mathrm{C}$, in PM2000 alloy. It is worth mentioning that the hardness of the PH 13-8 Mo in this study is twice that of the PM2000 alloy at $525{ }^{\circ} \mathrm{C}$. PM2000 is an early variant of ODS steels. The mechanical strength of ODS alloys is determined to a large amount by the oxide particle structure [19]. The oxide nanoclusters in the ODS alloy and the intermetallic nanoclusters formed here are hardly comparable but they provide a qualitative description of the role of the intermetallic nanoclusters in increasing high temperature mechanical properties in our alloy. At very high temperature, the precipitates (i.e. oxides in the 
ODS steel and intermetallic in the PH 13-8 Mo) are less effective since the hardness degrades from $300{ }^{\circ} \mathrm{C}$ to $600{ }^{\circ} \mathrm{C}$ by $3 \mathrm{GPa}$ in both cases.

Fig. 8a plots the values of YS, UTS and converted hardness measured with a Berkovich shaped indenter to a Vickers shaped indenter $(\mathrm{T} 1+\mathrm{T} 3)$ marked as $\mathrm{H} v$ s. temperature in the same graph. It is obvious that the data shows the same trend and that the material starts losing its strength at $400{ }^{\circ} \mathrm{C}$. However, the question of the relationship between tensile testing and hardness testing remains. In the literature a number of empirical equations are proposed [27, 3337]. To understand where these relationships are valid it is important to mention that in a number of these comparisons irradiated materials are utilized which show only very little to no work hardening [38]. While these empirical equations are based on direct comparisons only few physics based approaches exist. Most importantly to mention the work from Tabor [39] where the tensile flow stress is compared to the hardness numbers. While Tabor's work is clearly a fundamental based approach the work here considers only qualitative relationships but are discussed in the context of Tabors rules below. Fig. 8b shows a plot of the YS and UTS vs. calculated Vickers hardness using Eq. 1 derived from nanohardness data. The direct comparison between YS/UTS and hardness measurements over temperature is the first directly comparison conducted to the best of our knowledge and provides insight into the hardness vs. YS and UTS relationship.

Observing the plotted values on Fig. 8b, it is clear that there is a linear relationship between the UTS and the $\mathrm{HV}$ in the $300-600{ }^{\circ} \mathrm{C}$ temperature range.

However that trend does not hold true in the case of the YS and HV in the same temperature range. In order to understand this discrepancy one has to consider when tabors rules are valid and why.

Tabor pointed out that the linear relationship with a factor of 3 is only valid for ideal plastic materials so materials with little to no work hardening. This can be understood by the fact that underneath an indenter significant flow occurs and the simple linear correlation between hardness and YS is only valid if the material underneath the indenter does not harden significantly during deformation but rather flows in a homogeneous fashion. It is stated that if a material shows significant work hardening then the flow stress at $\sim 8-10 \%$ strain should be used rather than the yield stress. Unfortunately this is not possible in the samples here since the fracture occurs at already 5-7\% strain with significant work hardening as it can be seen by the vastly different numbers of YS and UTS at the tests conducted below $500{ }^{\circ} \mathrm{C}$. But at UTS no 
significant work hardening can occur any further and therefore the UTS and hardness numbers show a linear relationship. In addition at tests above $500{ }^{\circ} \mathrm{C}$ little to no work hardening is observed (only very small differences between YS and UTS) and therefore the relationship appears to be better.

\subsection{Indentation creep}

An in-depth study of the SRS on $\mathrm{Cr}$ and bcc metals (such as $\mathrm{Fe}$ ) was recently published by Wu et al. [40], where the measured $m$ values varied from 0.02 to 0.01 with decreasing grain size from $\sim \mathrm{mm}$ to $\sim \mu \mathrm{m}$ scale. Another study from Misra et al. exhibited $m$ and $V^{*}$ values of 0.06/0.13 and $48 \mathrm{~b}^{3} / 16 \mathrm{~b}^{3}$ for coarse-grained (CG) and nano-grained (NG)/ ultrafine-grained (UFG) austenitic stainless steels respectively [41,42]. Fig. 6a displays the $m$ values calculated from the creep data obtained for all three experiments. In that plot, low values are found at $300{ }^{\circ} \mathrm{C}$. It can be seen in the plot how $m$ increases at $400{ }^{\circ} \mathrm{C}$ and reaches a maximum at $525{ }^{\circ} \mathrm{C}$. In the work by Misra et al., the twinning mechanism was stated to be responsible for the increase of $m$ values in UFG/CG comparing with CG steel since twin boundaries acted as obstacles and restrained dislocation climbing $[42,43]$.

This study the low $m$ values at temperatures up to $400{ }^{\circ} \mathrm{C}$ can be explained by the presence of the intermetallic precursors that hinder dislocation motion [8]. At $450{ }^{\circ} \mathrm{C}$, an increase in $\mathrm{m}$ is visible, and it is associated with the bigger number of precipitates in the matrix. The $m$ value gets even higher at $500{ }^{\circ} \mathrm{C}$, reaching the maximum value of $0.30-0.35$ in the range $500-550{ }^{\circ} \mathrm{C}$. Leitner et al. suggested that in the early stages of aging, strengthening is associated with the stress required for dislocations to cut through coherent zones/precipitates and as the precipitates coarsen and become semi-coherent, the stress required for dislocations to cut the precipitates increases [8]. It is believed that in this region of temperature all the $\beta$-NiAl phase precipitates. Thus, the material will change to a bimodal microstructure. Leitner et al. found that aging at 525 ${ }^{\circ} \mathrm{C}$ for 3 hours results in the formation of two independent precipitation phases $(\beta-\mathrm{NiAl}$ and Tiphase rich) [5]. After $550{ }^{\circ} \mathrm{C}$, a decrease in $m$ value is found. This behavior can be attributed to a coarsened precipitate population, where a change from a bimodal distribution to coarsened state takes place. Schnitzer et al. [44] suggested that the effect of amounts of reverted austenite after longer aging times could be present as austenite is free of $\mathrm{NiAl}$ precipitates and thus, no pinning of dislocations due to precipitates is present in the austenite. Ping et al. said that small amounts of fine carbides are formed in the martensitic matrix at high annealing temperatures and at 620 
${ }^{\circ} \mathrm{C}$, in addition to the $\mathrm{NiAl}$ precipitates and carbides, reverted austenite grains were observed [10]. In this research, it is believed that the possible apparition of reverted austenite and fine carbides in the over-aged sample decreased the $m$-value, but still in the over-aged samples the formed precipitates remain in the matrix. The decrease in the m-value found for $\mathrm{T} 2$ could be explained by the expected bigger amount of reverse austenite after the two consecutive thermal cycles. Schnitzer et al. [44] observed that around $40 \%$ of the loss in strength during aging could be attributed to the presence of reverted austenite. Ping et al. suggested that the decrease in strength at higher temperatures (above $550{ }^{\circ} \mathrm{C}$ ) is attributed to the decrease in the number density of the NiAl precipitates and the reversion of austenite, and also larger carbides [10]. In this research, similar decrease in the hardness has been shown after aging at 625 and $650{ }^{\circ} \mathrm{C}$. One can speculate in the light of the relevant literature that precipitate coarsening occurs. Since the strength loss is rather dramatic, coarsening alone might not explain the pronounced property degradation alone and therefore one may speculate that the dislocation-precipitate interaction changes and dislocation climb becomes a more active mechanism. Obviously dislocation climb and precipitate coarsening can be related since both are based on vacancy motion and diffusion based mechanism. Contrary to the strain rate sensitivity, where the increase in $m$ is observed at $400{ }^{\circ} \mathrm{C}$, the activation volume shows a plateau of low values $\left(\sim 5 \mathrm{~b}^{3}\right)$ over temperatures up to 500 ${ }^{\circ} \mathrm{C}$. Between 500 and $550{ }^{\circ} \mathrm{C}$, just a small increase is observed. After that point, the $V^{*}$ increase up to $\sim 20 \mathrm{~b}^{3}$. This could be an indication of a remarkable change in the microstructure presumably due to the apparition of reverse austenite, as suggested by the strain rate sensitivity. It is interesting to note that no remarkable changes are seen in the $V^{*}$ until the apparition of reverse austenite.

\section{Conclusion}

In summary, tensile tests, in-situ nanoindentation hardness tests and creep tests at elevated temperature were conducted in PH 13-8 Mo in this work. The hardness, strain, yield stress, ultimate yield strength, total elongation, strain rate sensitivity and activation volume were determined at high temperature. The relationships between yield stress and hardness, and between tensile strength and hardness were shown for first time at high temperature.

The use of high-temperature mechanical testing techniques allows to probe the changes in the mechanical properties as the microstructure changes at different temperatures. The change in mechanical properties as a function of temperature indicated that intermetallic precipitate 
strengthening effect starts to take place at temperatures as low as $450{ }^{\circ} \mathrm{C}$. While the $\mathrm{H}$, strain, UTS, TE and $m$ start changing at $450{ }^{\circ} \mathrm{C}$; YS and $V^{*}$ did not change up to $500-550{ }^{\circ} \mathrm{C}$. The correlation between the hardness, YS, and UTS between 300-600 ${ }^{\circ} \mathrm{C}$ and between 500 and 600 ${ }^{\circ} \mathrm{C}$ is discussed in the light of Tabors work.

An increase of $m$ values with temperatures was presented up to $525{ }^{\circ} \mathrm{C}$. Higher $\mathrm{m}$ values at elevated temperatures implied that dislocation climb dominated the deformation process. $V^{*}$ did not change up to the peak temperature for the hardness of the material $\left(525^{\circ} \mathrm{C}\right)$, even with the continuous precipitation of the different precipitates. After that point, $V^{*}$ starts increasing and it is associated to the dislocation climb mechanism and a possible precipitate coarsening and a reduction of the precipitate density over $600{ }^{\circ} \mathrm{C}$. Quantification of the mechanical properties at high temperature of $\mathrm{PH}$ 13-8 provides valuable insight into how the precipitation hardening occurs and provides useful feedback for finite element modeling of its behavior at high temperature.

\section{Acknowledgements}

The program was supported by DOE-NEET program. The Chinese Government Graduate Student Overseas Study Program also provided student funding for this work. 


\section{$\underline{\text { References }}$}

[1] S. Hossein Nedjad, S. Meimandi, A. Mahmoudi, T. Abedi, S. Yazdani, H. Shirazi, M. Nili Ahmadabadi, Mater. Sci. Eng., A 501 (2009) 182-187

[2] G. Pantazopoulos, T. Papazoglou, P. Psyllki, G. Sfantos, S. Antoniou, K. Papadimitriou, J. Sideris, Surf. Coat. Technol. 187 (2004) 77-85.

[3] R.B. Frandsen, T. Chrstiansen, M.A.J. Somers, Surf. Coat. Technol. 200 (2006) 5160-5169.

[4] R. Schnitzer, R. Radis, M. Nöhrer, M. Schober, R. Hochfellner, S. Zinner, E. PovodenKaradeniz, E. Kozeschnik, H. Leitner, Mater. Chem. Phys. 122 (2010) 138-145.

[5] H. Leitner, R. Schnitzer, M. Schober, S. Zinner, Acta Mater. 56 (2011) 5012-5022.

[6] J. Mittra, G.K. Dey, D. Seb, A.K. Patra, S. Mazumder, P.K. De, Scripta Mater. 51 (2004) 349-353.

[7] S. Höring, D. Abou-Ras, N. Wanderka, H. Leitner, H. Clemens, J. Banhart, Steel Research International 80 (2009) 84-88.

[8] H. Leitner, M. Schober, R. Schnitzer, S. Zinner, Mater. Sci. Eng., A 528 (2011) 5264-5270.

[9] V. Seetharaman, M. Sundararaman, R. Krishnan, Mater. Sci. Eng., A 47 (1981) 1-11.

[10] D.H. Ping, M. Ohnuma, Y. Hirakawa, Y. Kadoya, K. Hono, Mater. Sci. Eng., A 394 (2005) 285-295.

[11] J. Mittra, U.D. Kulkarni, G.K. Dey, Mater. Sci. Eng., A 500 (2009) 244-247.

[12] S.P. Bruhl, R. Charadia, S. Simison, D.G. Lamas, A. Cabo, Surf. Coat. Technol. 204 (2010) 3280-3286.

[13] C. Hofer, E. Stergar, S.A. Maloy, Y. Wang, P. Hosemann, J. Nucl. Mater. 458 (2015) 316368.

[14] J.M. Wheeler, D.E.J. Armstrong, W. Heinz, R. Schwaiger, Curr. Opin. Solid State Mater. Sci. (online) 2015.

[15] M. Rebelo de Figueiredo, M.D. Abad, A.J. Harris, C. Mitterer, P. Hosemann, Thin Solid Films 578 (2015) 20-24

[16] J.M. Wheeler, V. Maier, K. Durst, M. Goken, J. Michler, Mater. Sci. Eng., A 585 (2013) 108-113.

[17] M. Kreuzeder, M.D. Abad, M.-M. Primorac, P. Hosemann, V. Maier, D. Kiener, J. Mater. Sci. 50 (2014) 634-643 
[18] M.-M. Primorac, M.D. Abad, P. Hosemann, M. Kreuzeder, V. Maier, D. Kiener, Mater. Sci. Eng., A 625 (2015) 296-302.

[19] Z. Huang, A. Harris, S.A. Maloy, P. Hosemann, J. Nucl. Mat. 451 (2014) 162-167.

[20] D. Peykov, E. Martin, R. Chromik, R. Gauvin, M. Trudeau, J. Mater. Sci. 47 (2012) 71897200.

[21] <http://www.bucorp.com/corrax_p.htm>. s.l.: Boehler-Uddeholm, August 2014.

[22] N. Everitt, M. Davies, J. Smith, Philos. Mag. 91 (2011) 1221-1244.

[23] J.M. Wheeler, J. Michler, Review of Scientific Instruments 84 (2013).

[24] W.C. Oliver, G.M. Pharr, J. Mater. Res. 7 (1992) 1564-1583.

[25] R. Schnitzer, R. Radis, M. Nöhrer, M. Schober, R. Hochfellner, S. Zinner, E. PovodenKaradeniz, E. Kozeschnik, H. Leitner, Acta Mater. 59 (2011) 5012-5022.

[26] A.C. Fischer-Cripps, Nanoindentation, Springer, 2004, 26, 269

[27] A. Lupinacci. K. Chen, Y. Li, M. Kunz, Z. Jiao, G.S. Was, M.D. Abad, A.M. Minor, P. Hosemann, J. Nucl. Mater. 458 (2015) 70-76.

[28] H. Li, A.H.W. Ngan, J. Mater. Res. 19 (2004) 513-522.

[29] Z. Ma, S. Long, Y. Pan, Y. Zhou, J. Mater. Sci. 43 (2008) 5952-5955.

[30] M.B. Toloczko, M.L. Hamilton, S.A. Maloy, J. Nucl. Mater 318 (2003) 200-206.

[31] K.K. Bae, K. Ehrlich, A. Möslang, J. Nucl. Mater 191-194 (1992) 905-909.

[32] A. Reichardt, A. Lupinacci, J. Kacher, Z. Jiao, P. Chou, M.D. Abad, A.Minor, P.Hosemann, Proceedings of Fontevraud 8 - Contribution of Materials Investigations and Operating Experience to LWRs' Safety, Performance and Reliability. Avignon, France (September 14$18,2014)$

[33] S. Bruemmer, D. Edwards, E. Simonen, Characterization of Neutron-Irradiated 300-Series Stainless Steels to Assess Mechanisms of Irradiation-Assisted Stress Corrosion Cracking: Volume 1: LWR-Irradiated Type 304 and 316SS Heats with Established IASCC Susceptibility, EPRI, Palo Alto, CA: 2001. 1001496.

[34] M. Toloczko, G. Lucas, G. Odette, R. Stoller, M. Hamilton, An investigation of microstructures and yield strength in irradiated austenitic stainless steels using small specimen techniques, in: 17th Int. Symp. Eff. Radiat. Mater., ASTM STP 1270, 1996, pp. 902.

[35] R. Rodriguez, I. Gutierrez, Mat. Sci. Eng., A 361 (2003) 377-384. 
[36] M. Gasko, G. Rosenberg, Materials Engineering-Materialove Inzinierstvo 18 (2011) 155159.

[37] E.J. Pavlina, C.J. Van Tyne, J. Mater. Eng. Perform. 17 (2008) 888-893.

[38] J.T. Busby, M.C. Hash, G.S. Was, Journal of Nuclear Materials, 336 (2005) 267-278.

[39] D. Tabor, The Hardness of Metals, Oxford University Press, New York, 1951.

[40] D. Wu, X.L. Wang, T.G. Nieh, J. Phys. D: Appl. Phys. 47 (2014) 175303.

[41] R.D.K. Misra, Z. Zhang, Z. Jia, P.K.C. Venkatsurya, M.C. Somani, L.P. Karjalainen, Mater. Sci. Eng., A 548 (2012) 161-174.

[42] R.D.K. Misra, P. Venkatsurya, K.M. Wu, L.P. Karjalainen. Mater. Sci. Eng., A 560 (2013) 693-699.

[43] M.E. Kassner, M.-T. Perez-Prado, Fundamentals of creep in metals and alloys, Elsevier, Netherlands, 2004.

[44] R. Schnitzer, G.A. Zickler, E. Lach, H. Clemens, S. Zinner, T. Lippmann, H. Leitner, Mater. Sci. Eng., A 527 (2010) 2065-2070. 


\section{Figure Captions}

Figure 1. a) Scheme of the heating procedure during the nanoindentation tests. b) A drawing of the tensile specimen with size of 0.02 " thickness, 0.25 " gage width, 1.25 " gage length, and 4.72 " total length used in the experiments.

Figure 2. a) Optical microscopy image and b) XRD difractogram of the sample as-received.

Figure 3. a) The loading sequence for a constant-load indentation creep experiment at $525^{\circ} \mathrm{C}$. b) Representative load-displacement curves obtained during temperature cycle $\mathrm{T} 1$.

Figure 5. Strain versus time curves of T1 (a), T2 (b) and T3 (c), and strain at the end of the dwell time for the three temperature cycles (d).

Figure 4. Nanoindentation hardness at elevated temperature in temperature cycle T1 (a), T2 (b) and T3 (c). d) Nanoindentation and Vickers hardness of the as-received and after the different thermal treatment samples $v s$. maximum temperature.

Figure 6. Strain rate sensitivy (a) and activation volume (b) of T1+T3 and T2 vs. temperature.

Figure 7. Yield stress (a), ultimate tensile strength (b) and total elongation (c) of high temperature tensile tests. All datasets filled with green solid symbols were from specimens with 30 minute-hold time at temperature while orange open ones had a 4 hour-hold time.

Figure 8. (a) Yield stress, ultimate tensile strength and the converted Vickers hardness $\mathrm{H} v s$. temperature. (b) Yield stress and ultimate tensile strength $v s$. Vickers hardness $\mathrm{H}$. 


\section{Table Captions}

Table I: Chemical composition of PH 13-8 Mo maraging steel.

Table II: Test parameters and mechanical properties obtained by HT nanoindentation for the temperature cycles $\mathrm{T} 1, \mathrm{~T} 2$ and $\mathrm{T} 3$.

Table III. Test parameters and yield stress (YS), ultimate tensile strength (UTS) and total elongation (TE) obtained by HT tensile tests. 
a)

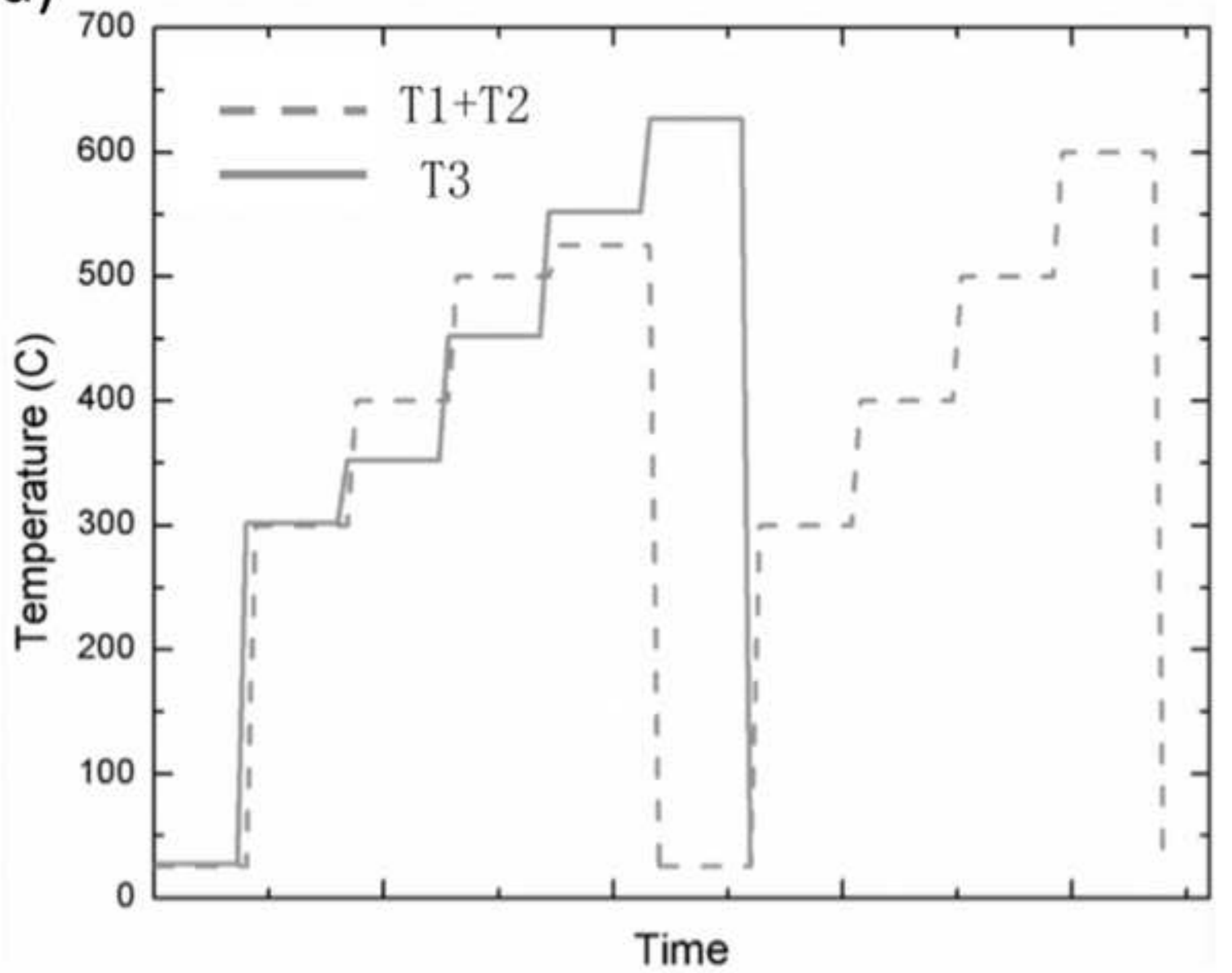

Time 
b)

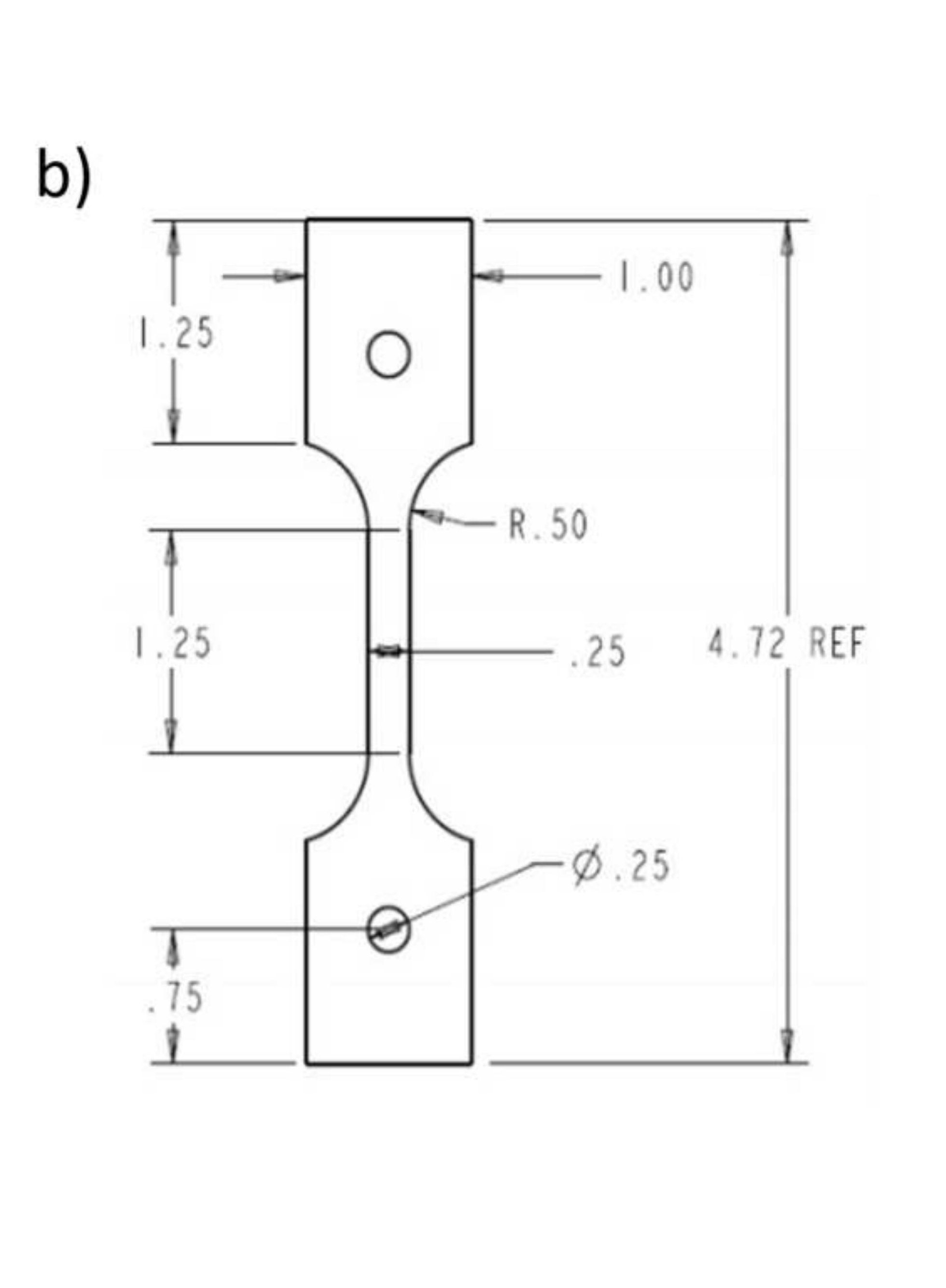

Figure 1b

(
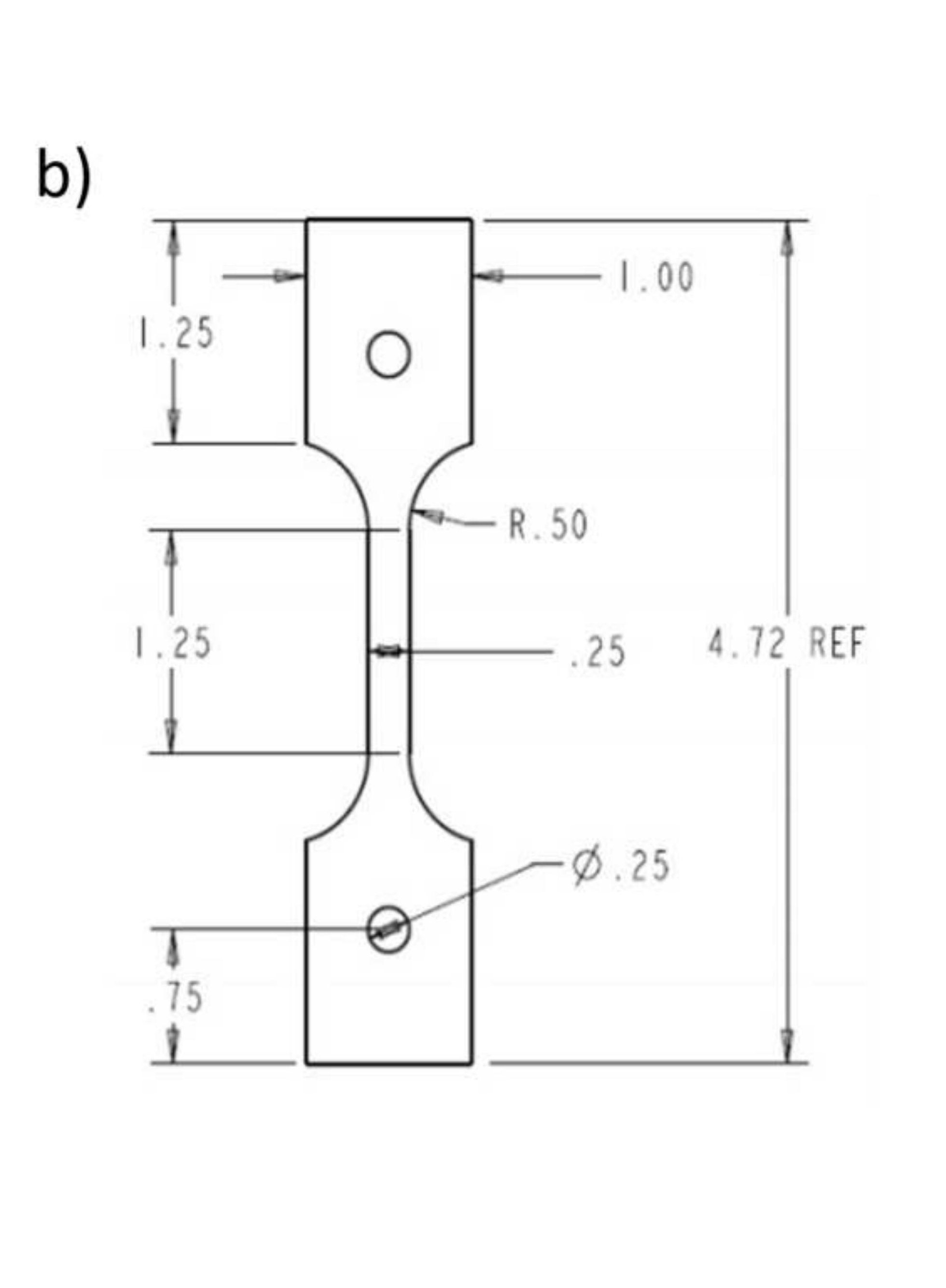
a) As received.
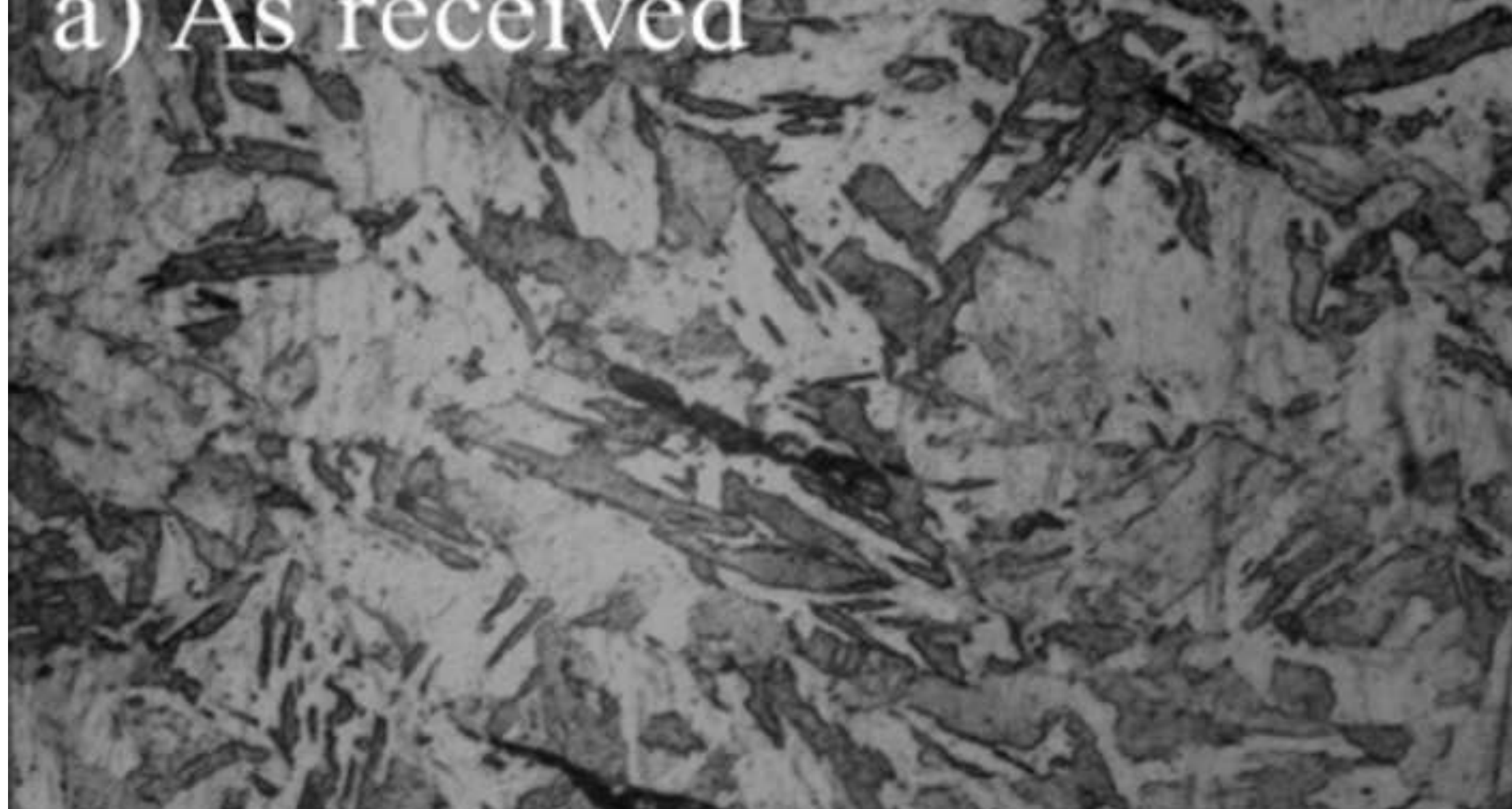

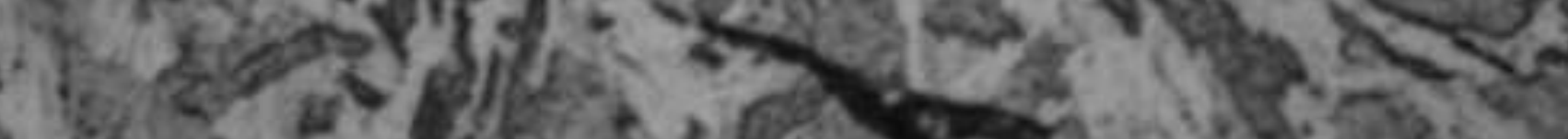

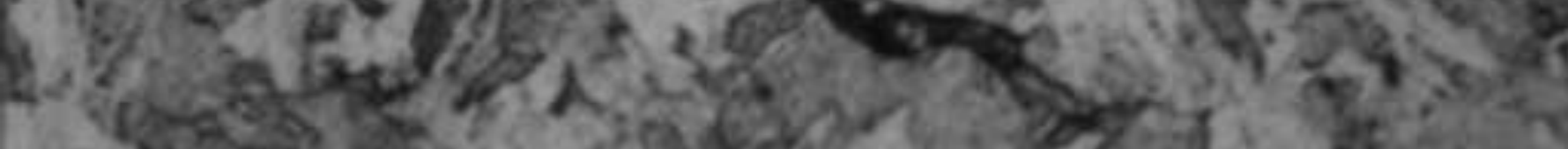

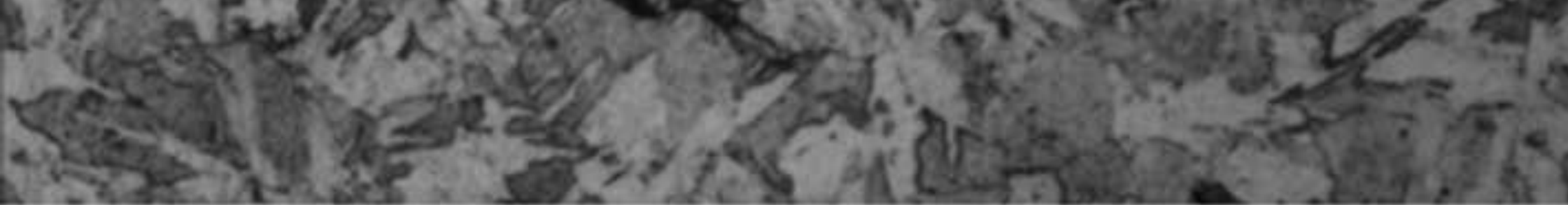




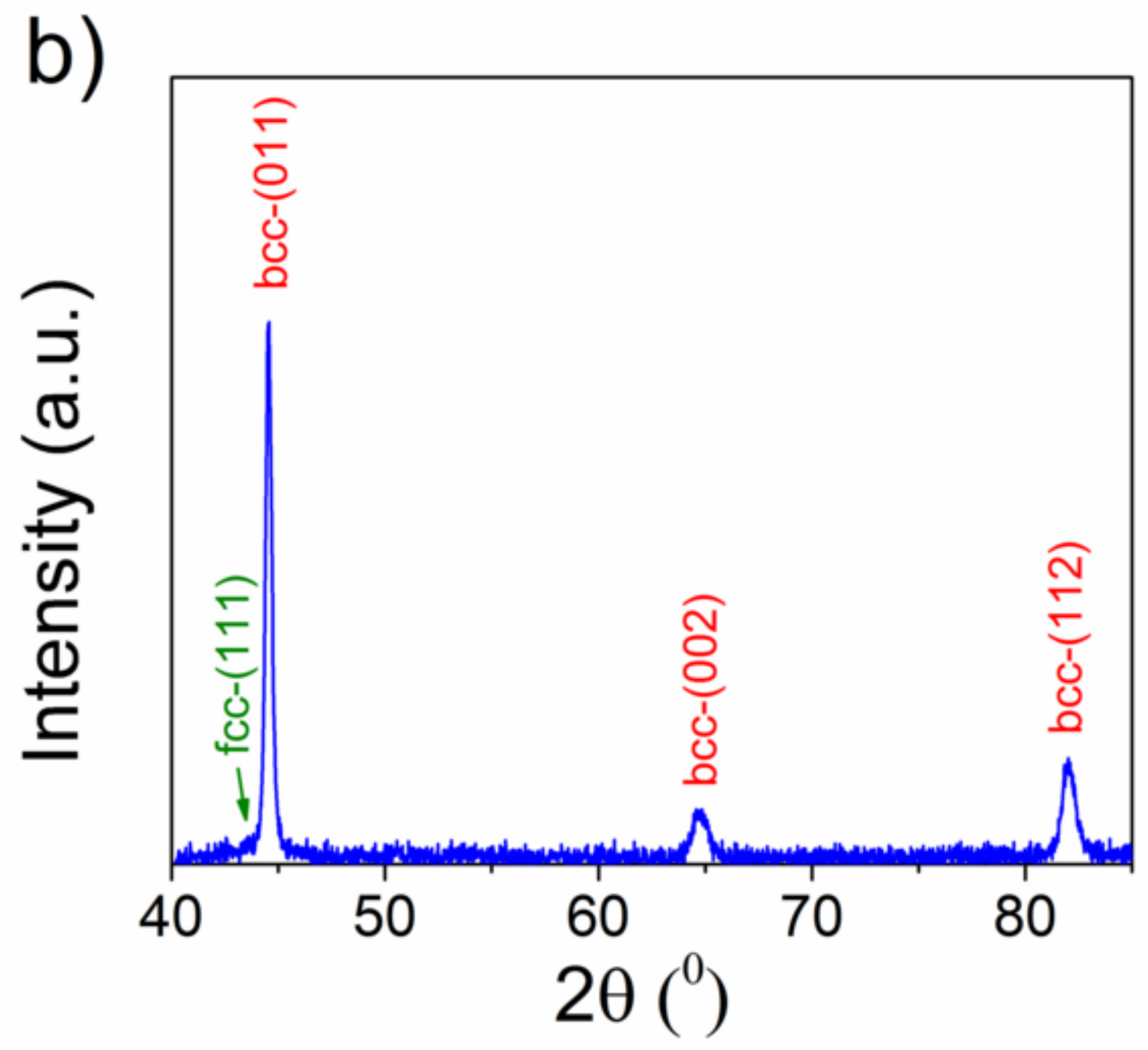


a)

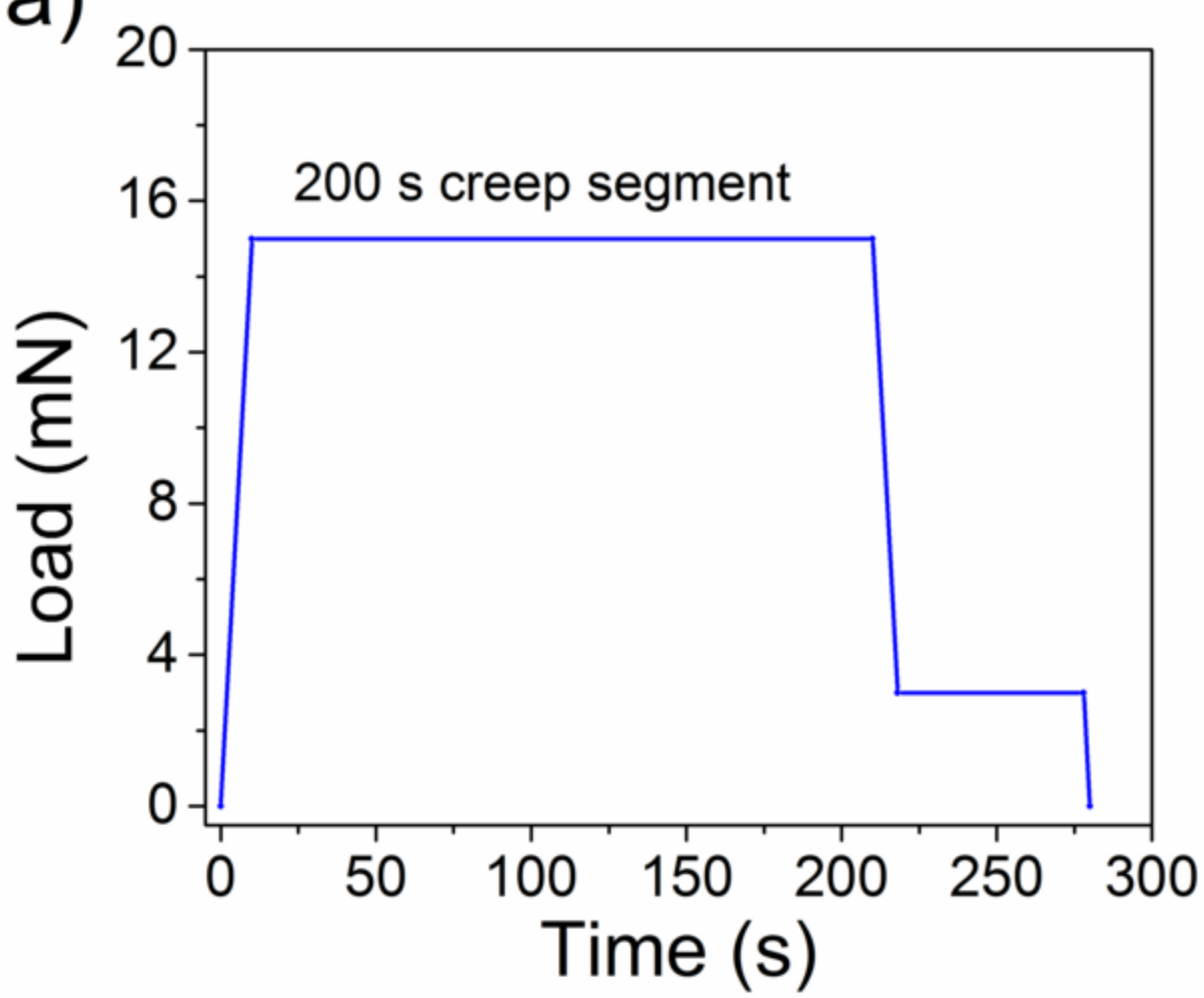




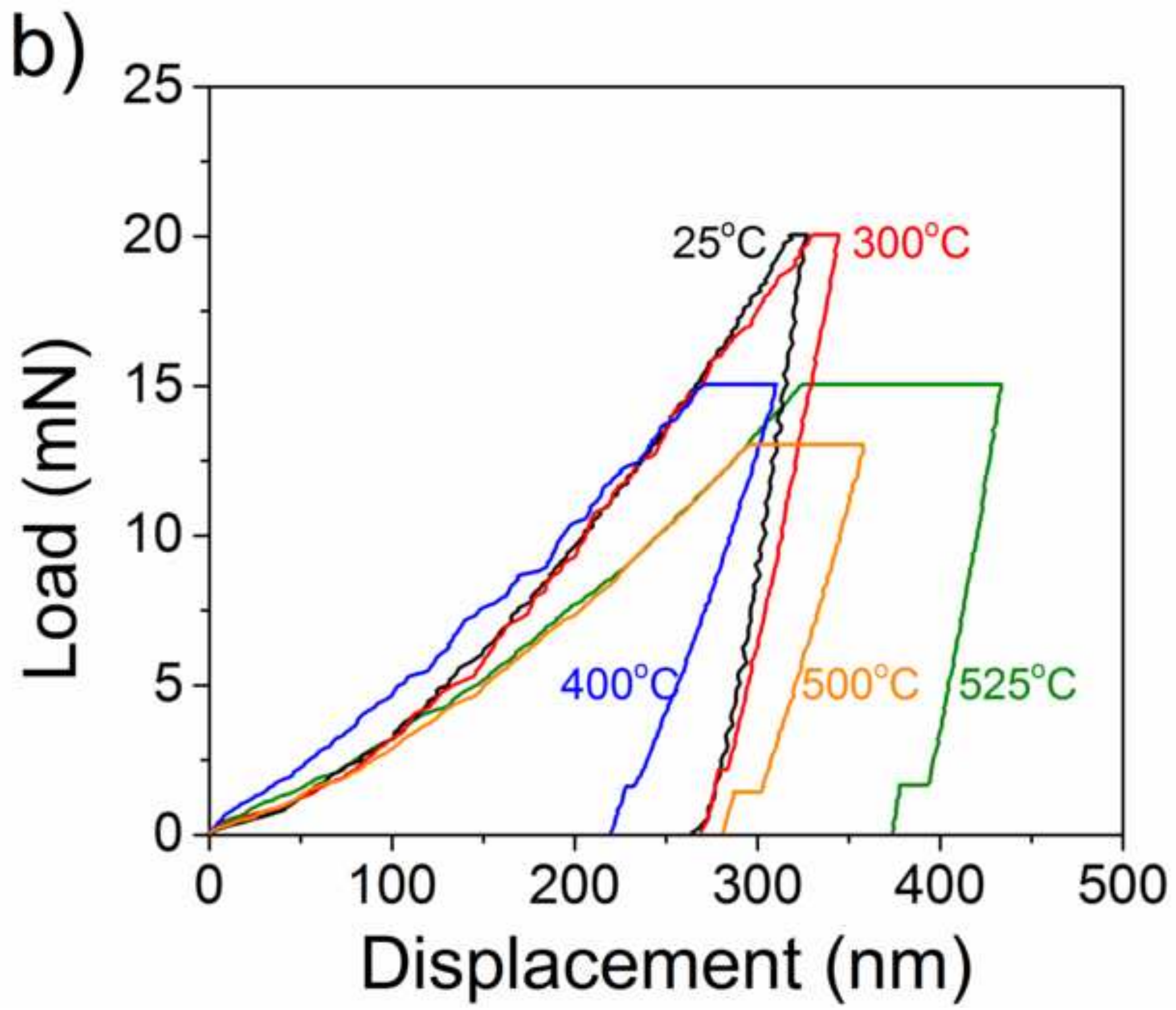




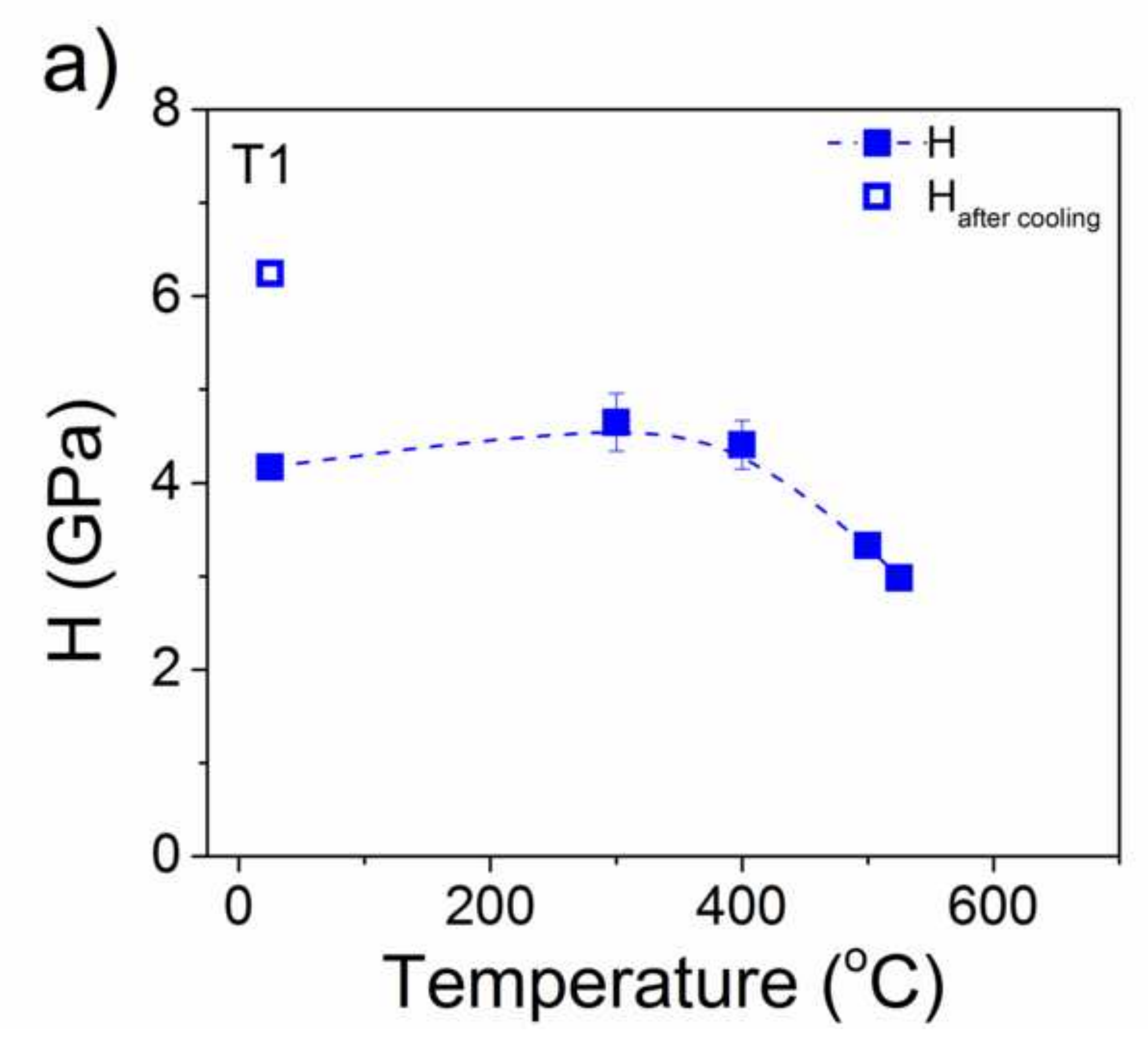




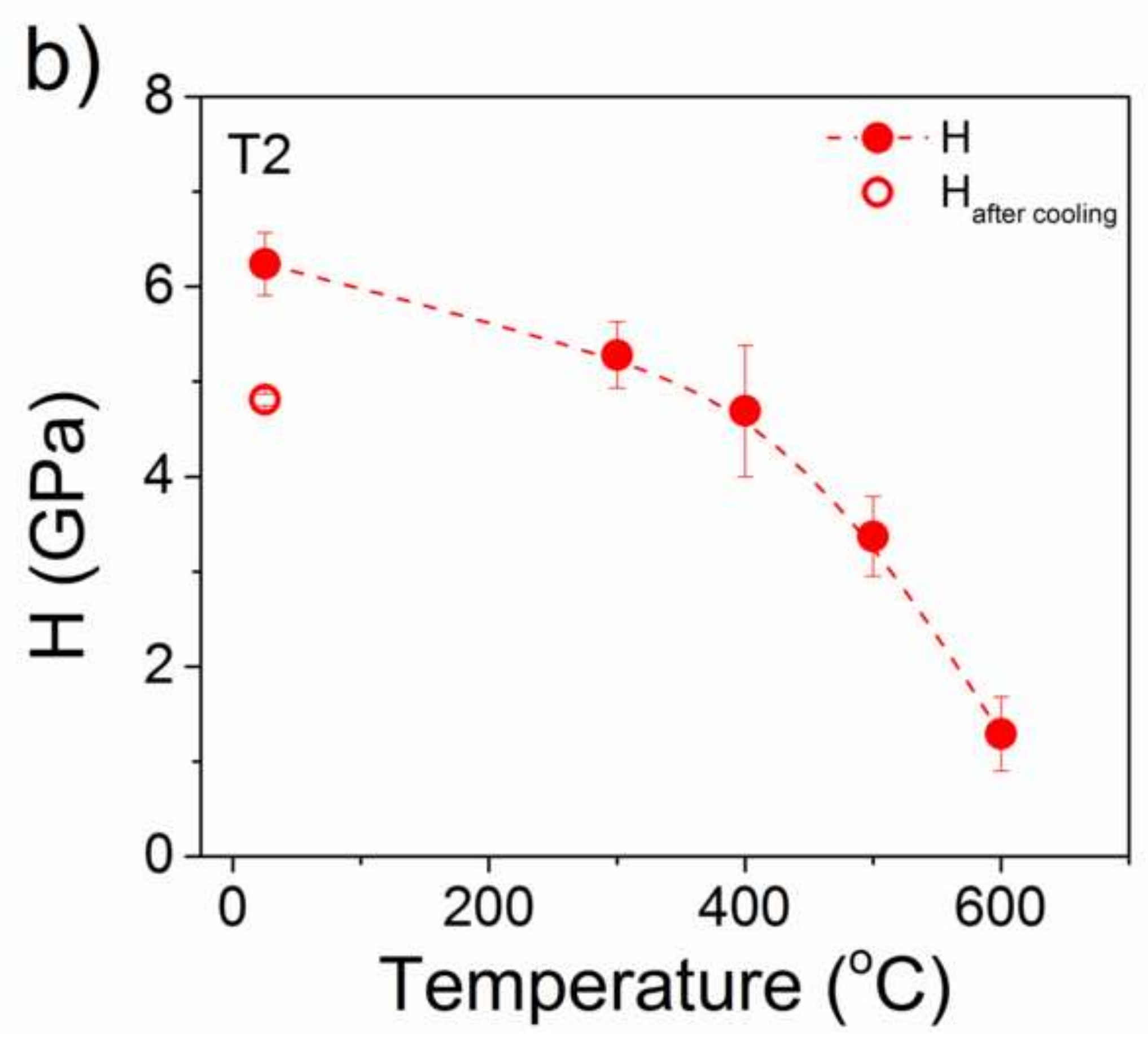




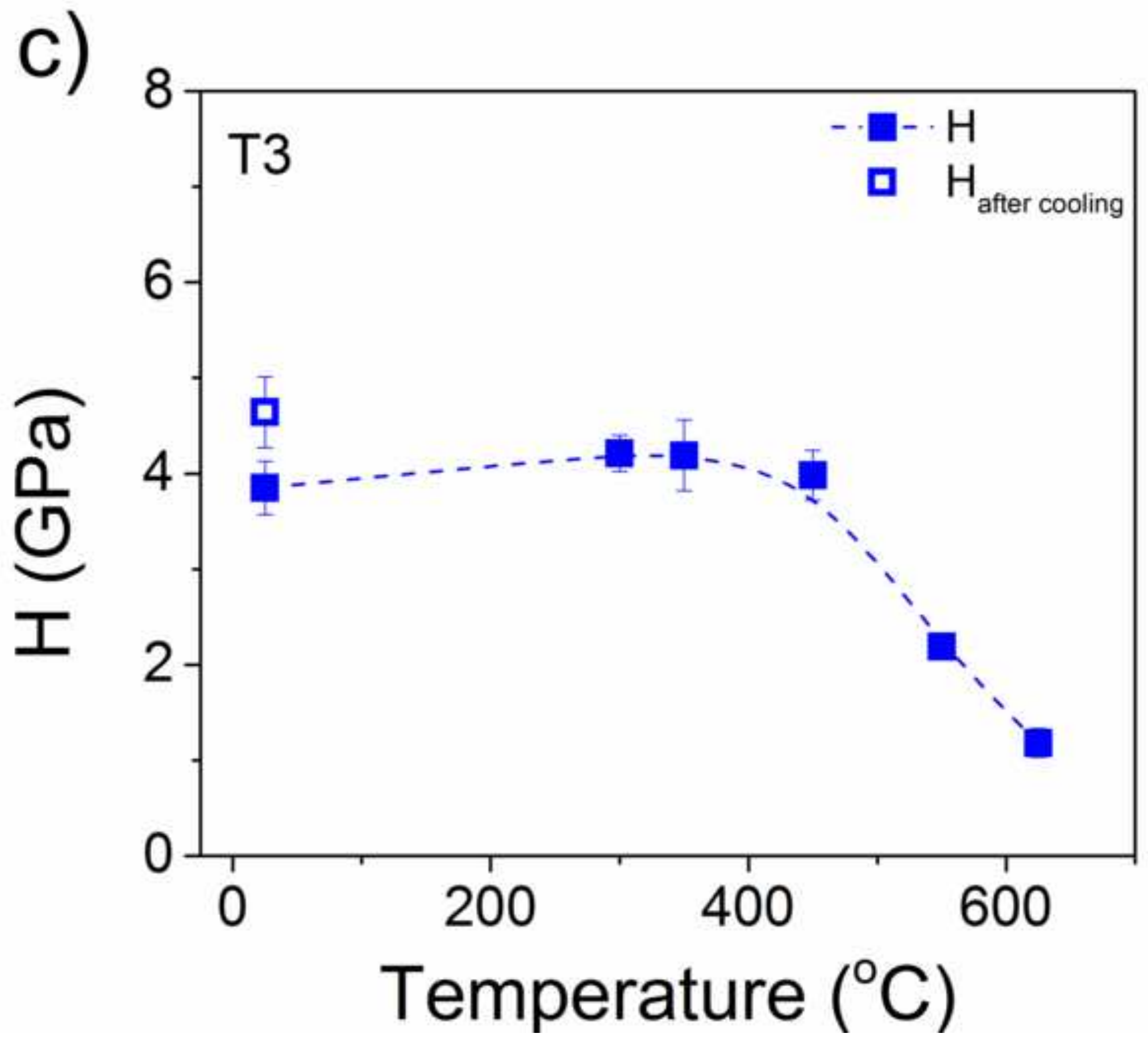


a) 1.0

T1

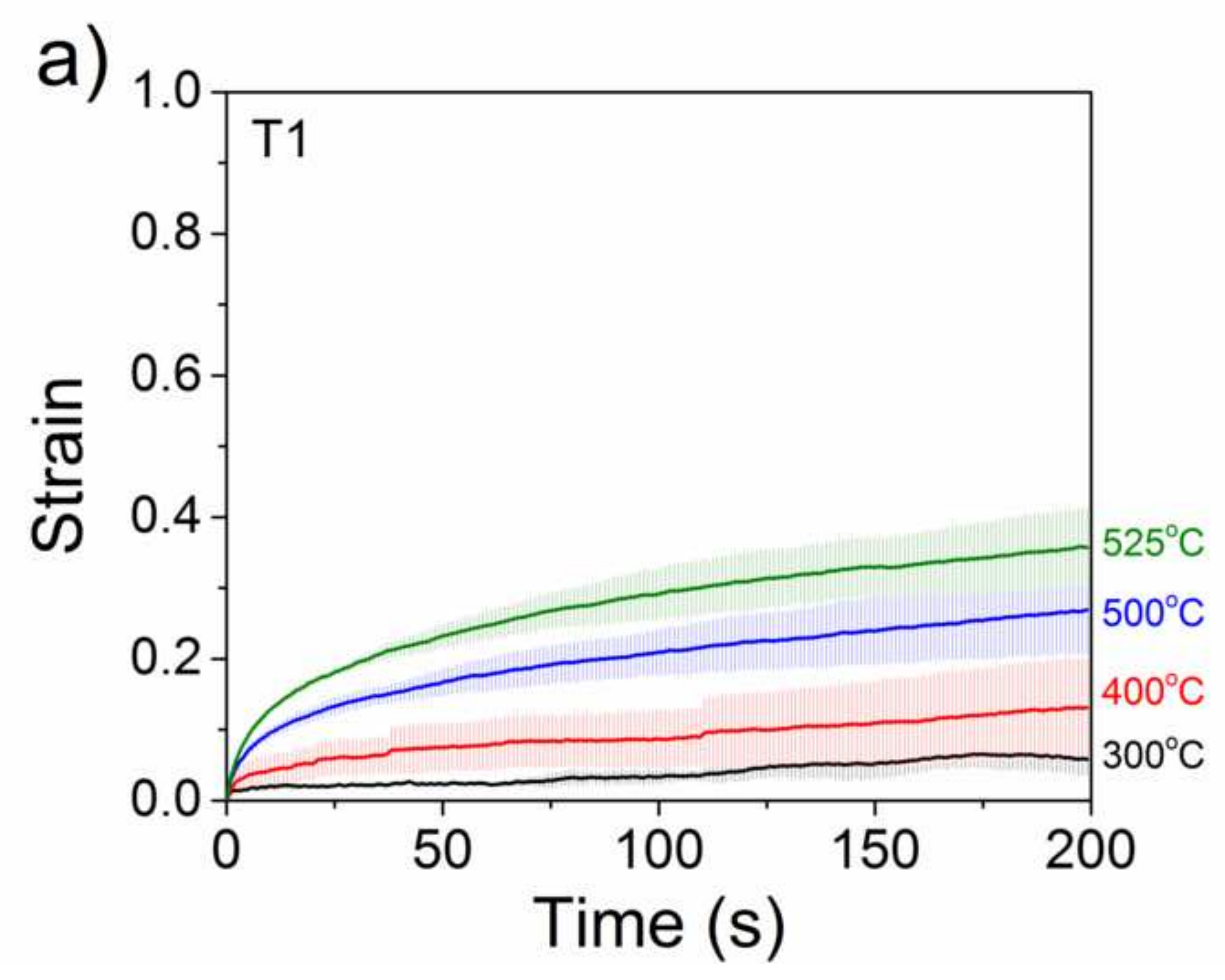




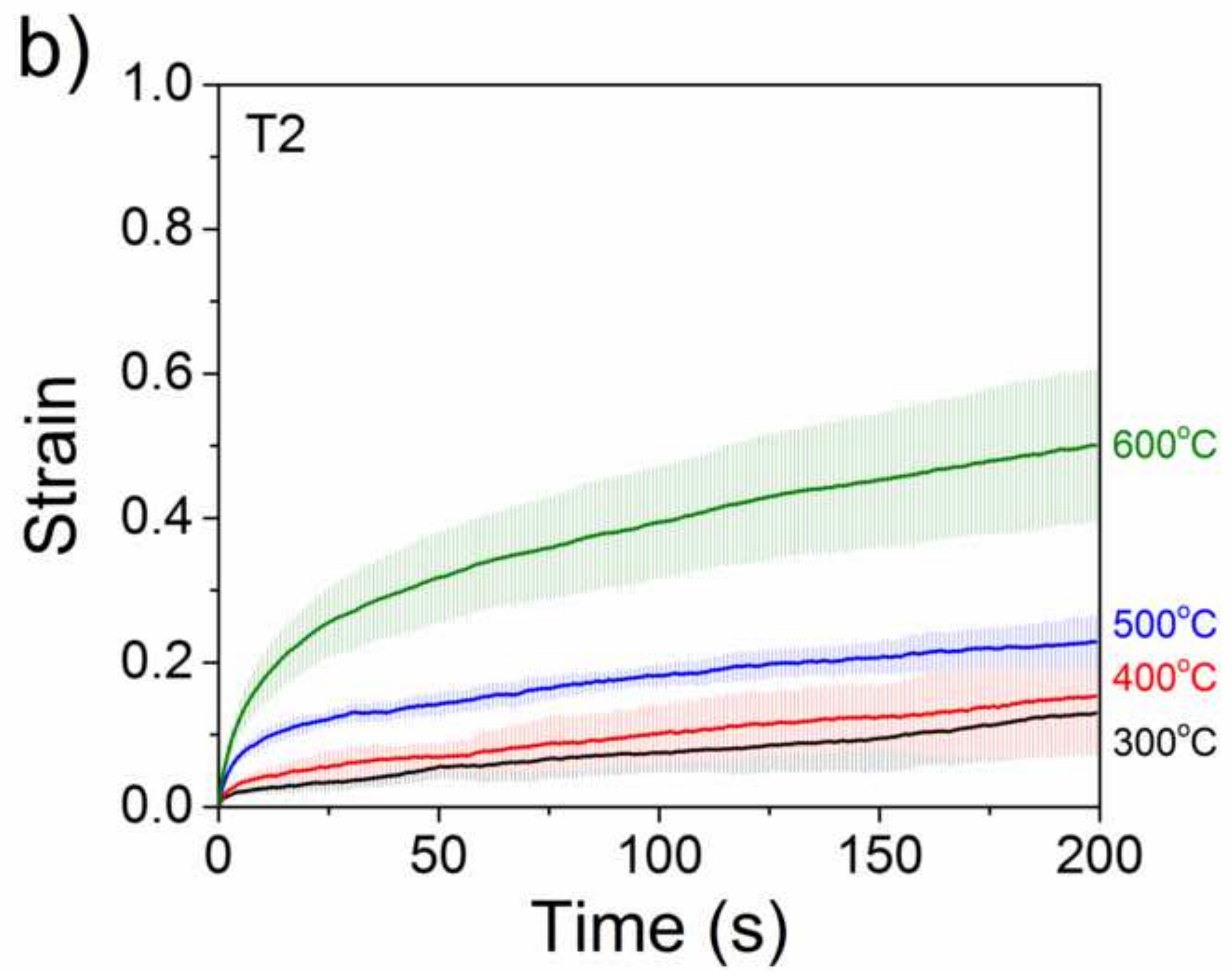




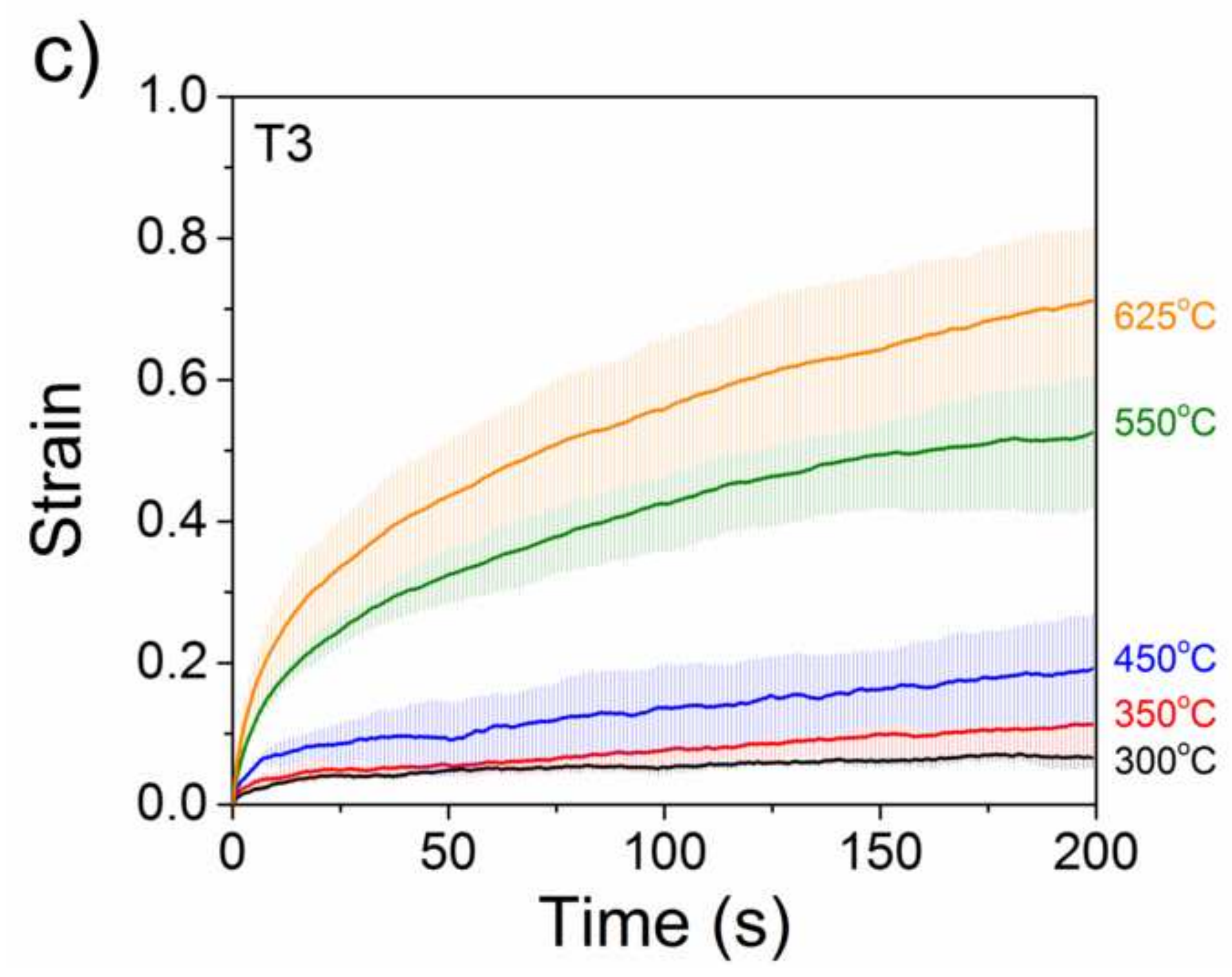

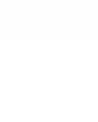


d)

$$
\begin{aligned}
& -\mathbf{D}-\mathrm{T} 1+\mathrm{T} 3 \\
& -\mathrm{O}-\mathrm{T} 2
\end{aligned}
$$

0.8

증 은

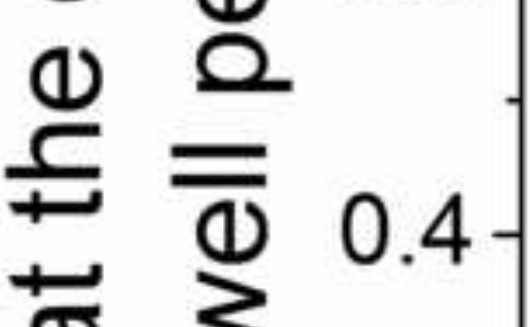

它

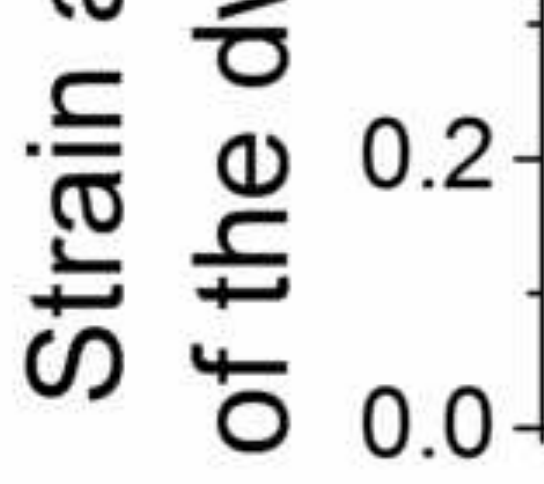

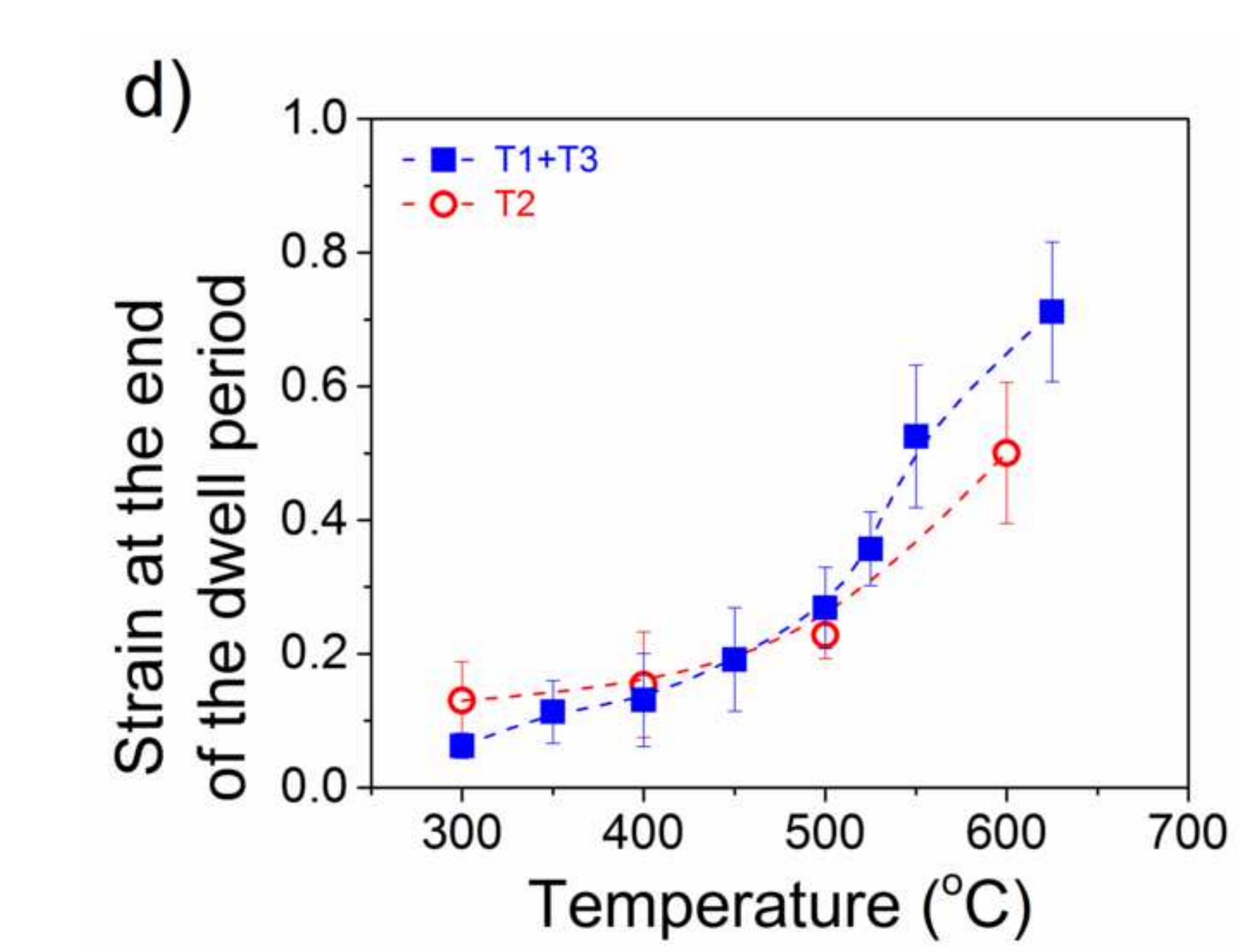




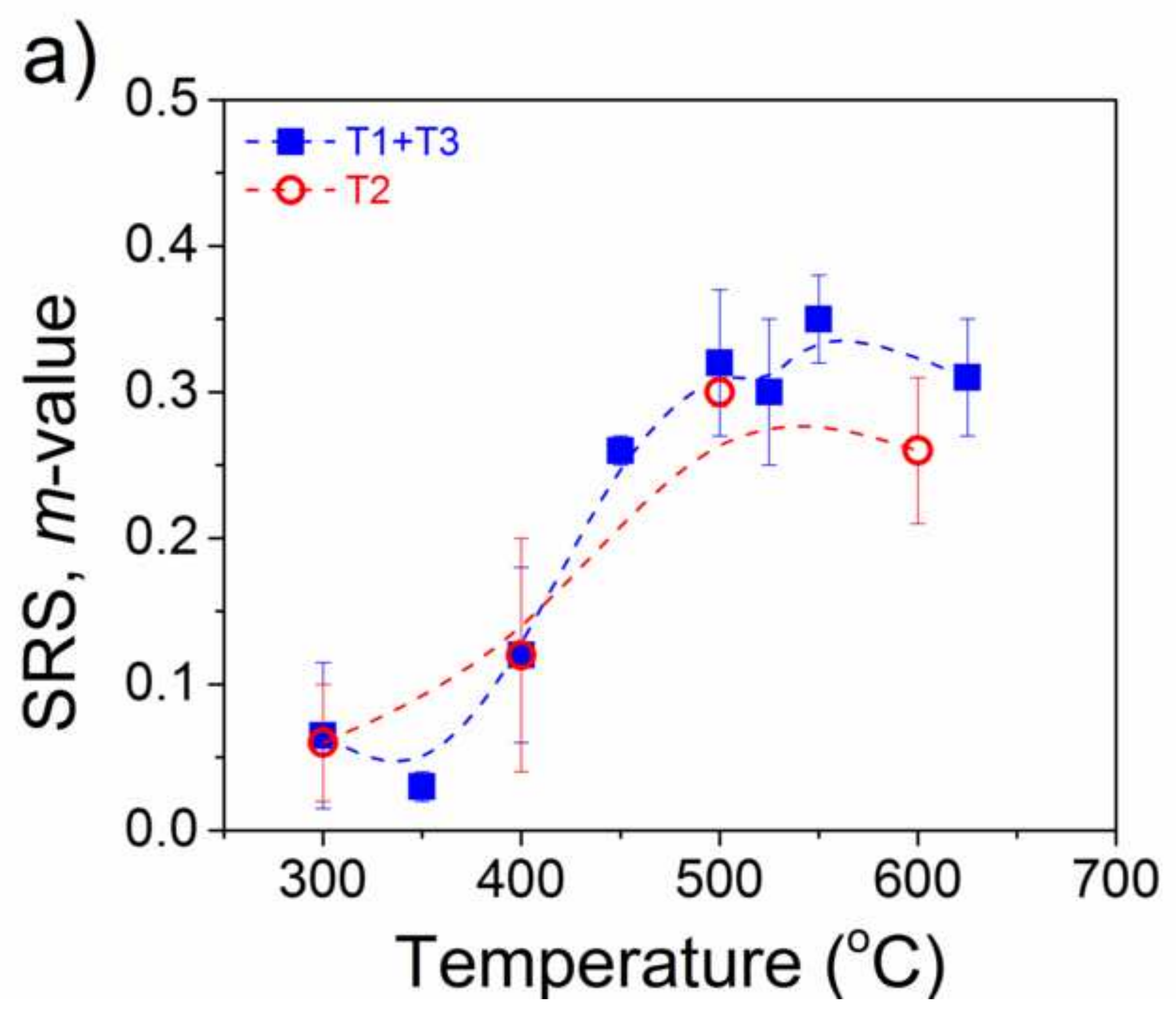




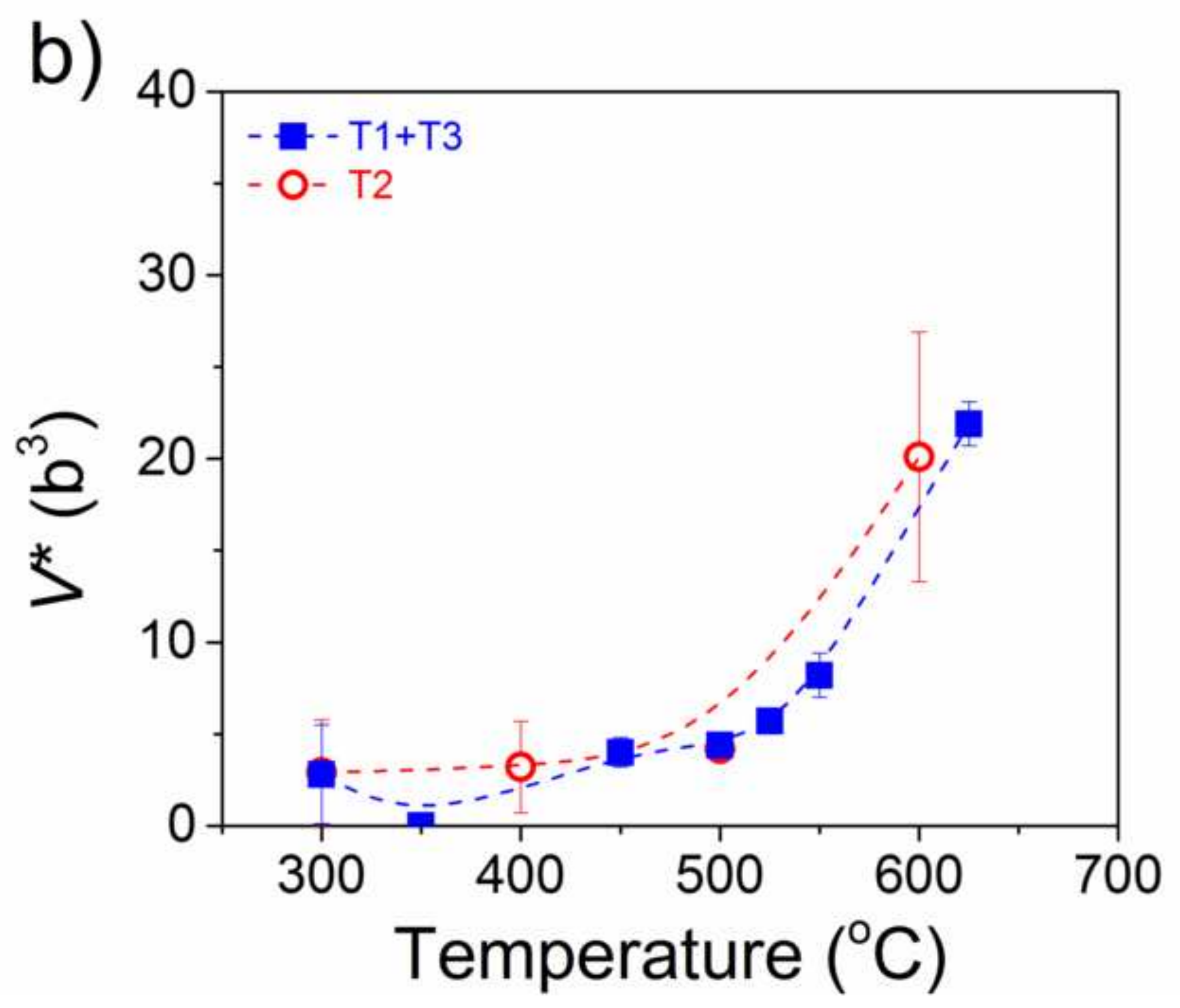




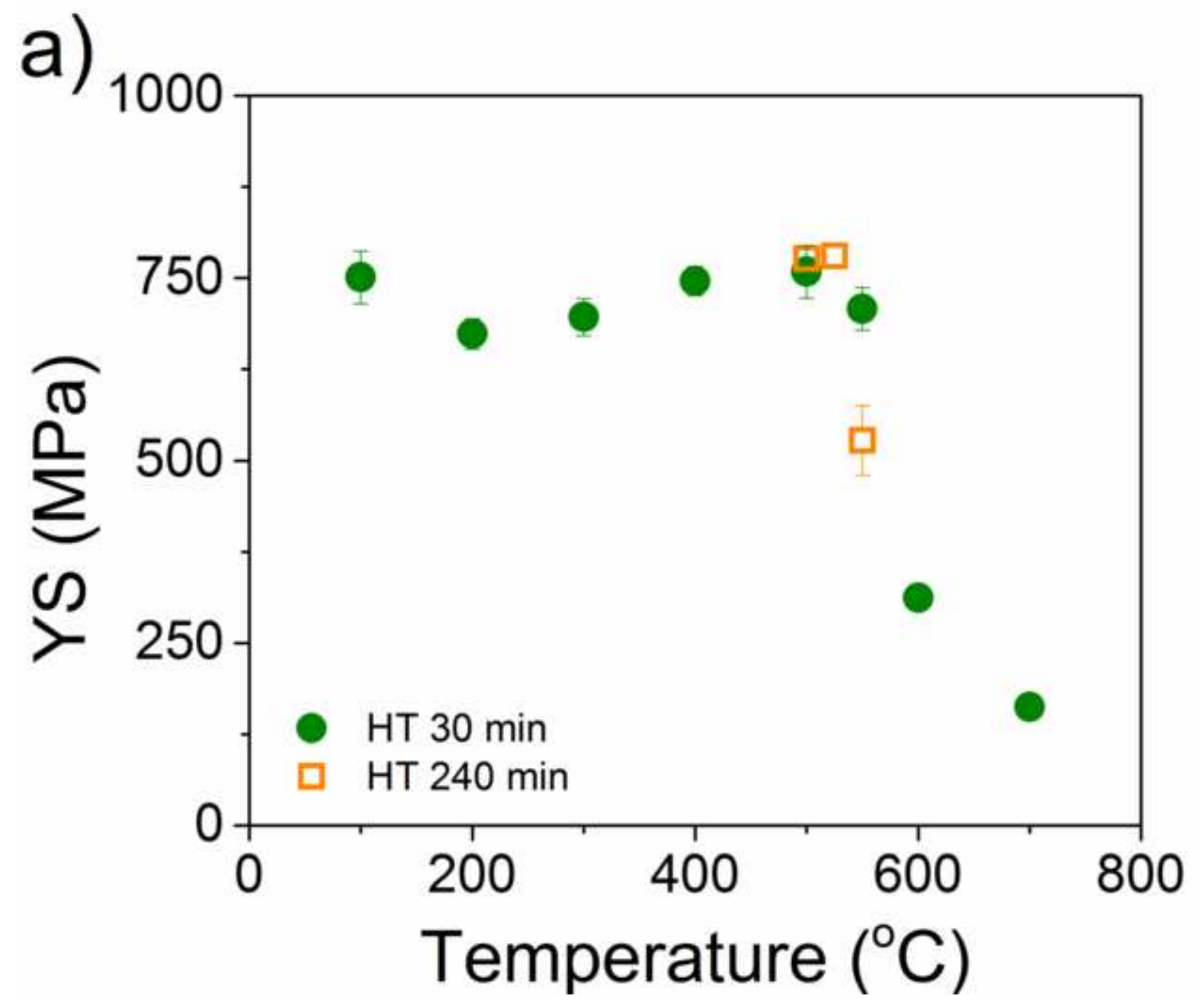




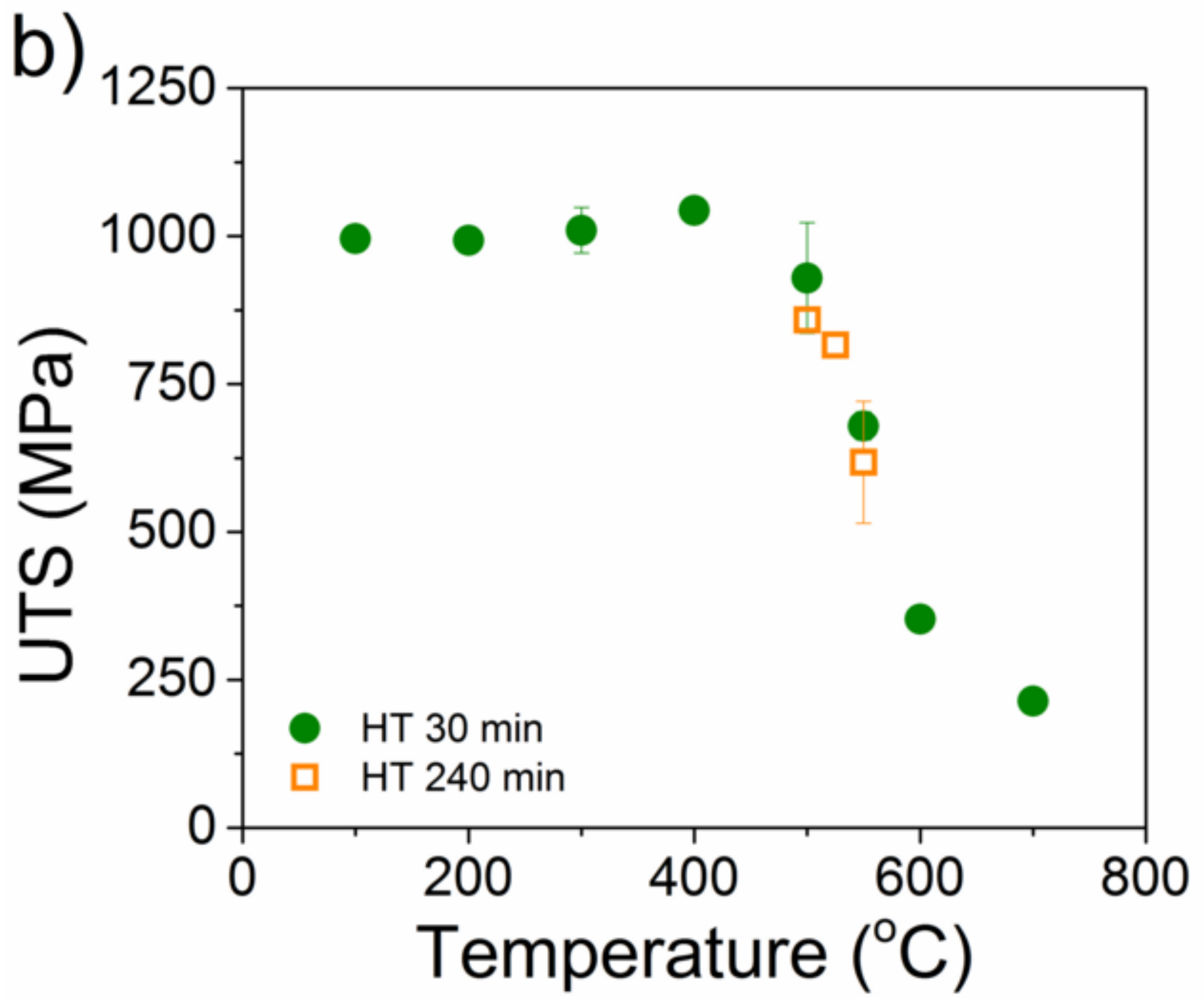


c)

100

$80-\begin{array}{ll}\bullet & \text { HT } 30 \mathrm{~min} \\ \square & \text { HT } 240 \mathrm{~min}\end{array}$

ฮำ

ए

$$
80
$$

$60-$

40

20

0

0

200

400

600

800

Temperature $\left({ }^{\circ} \mathrm{C}\right)$ 
a)

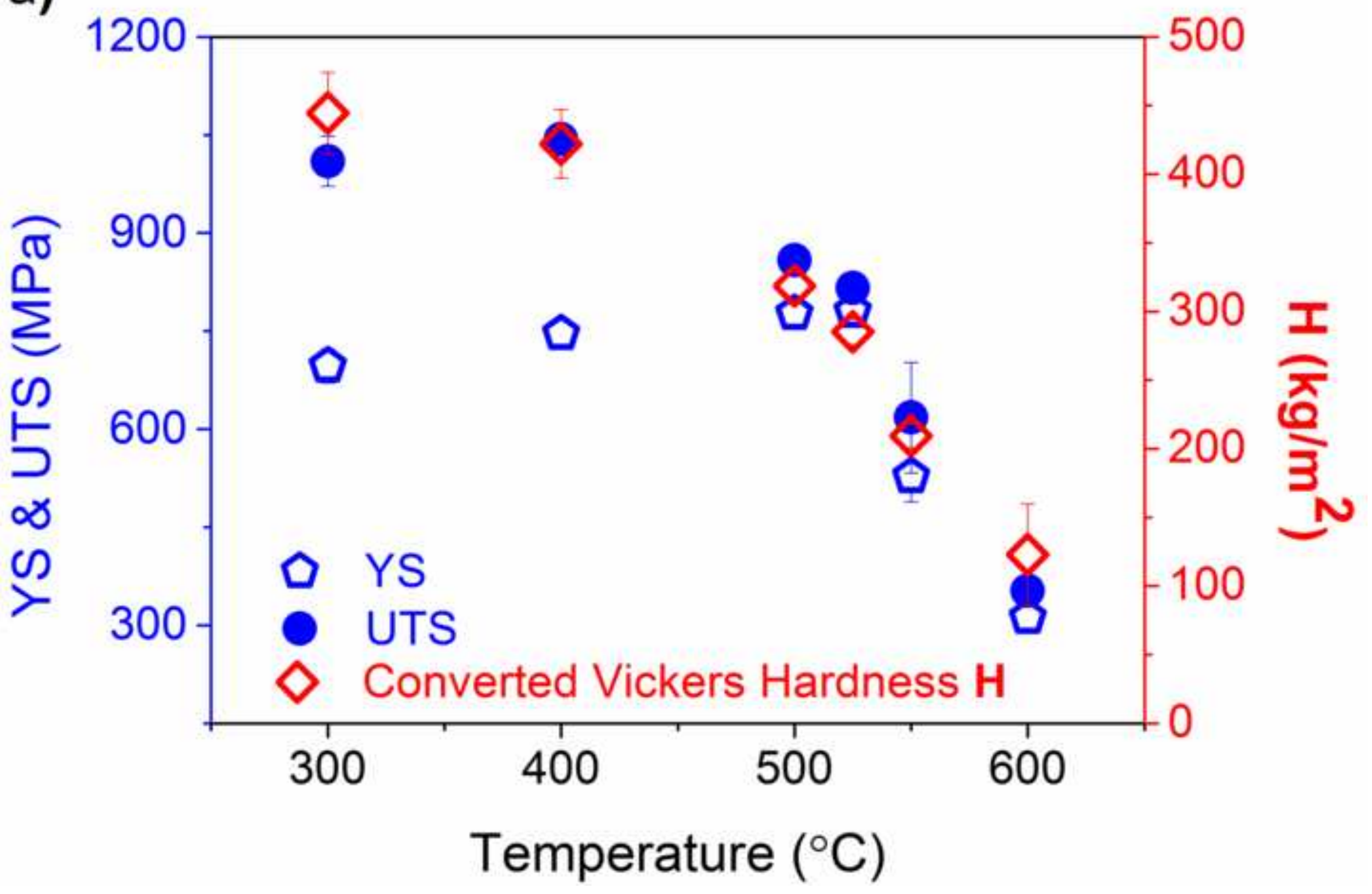


b)

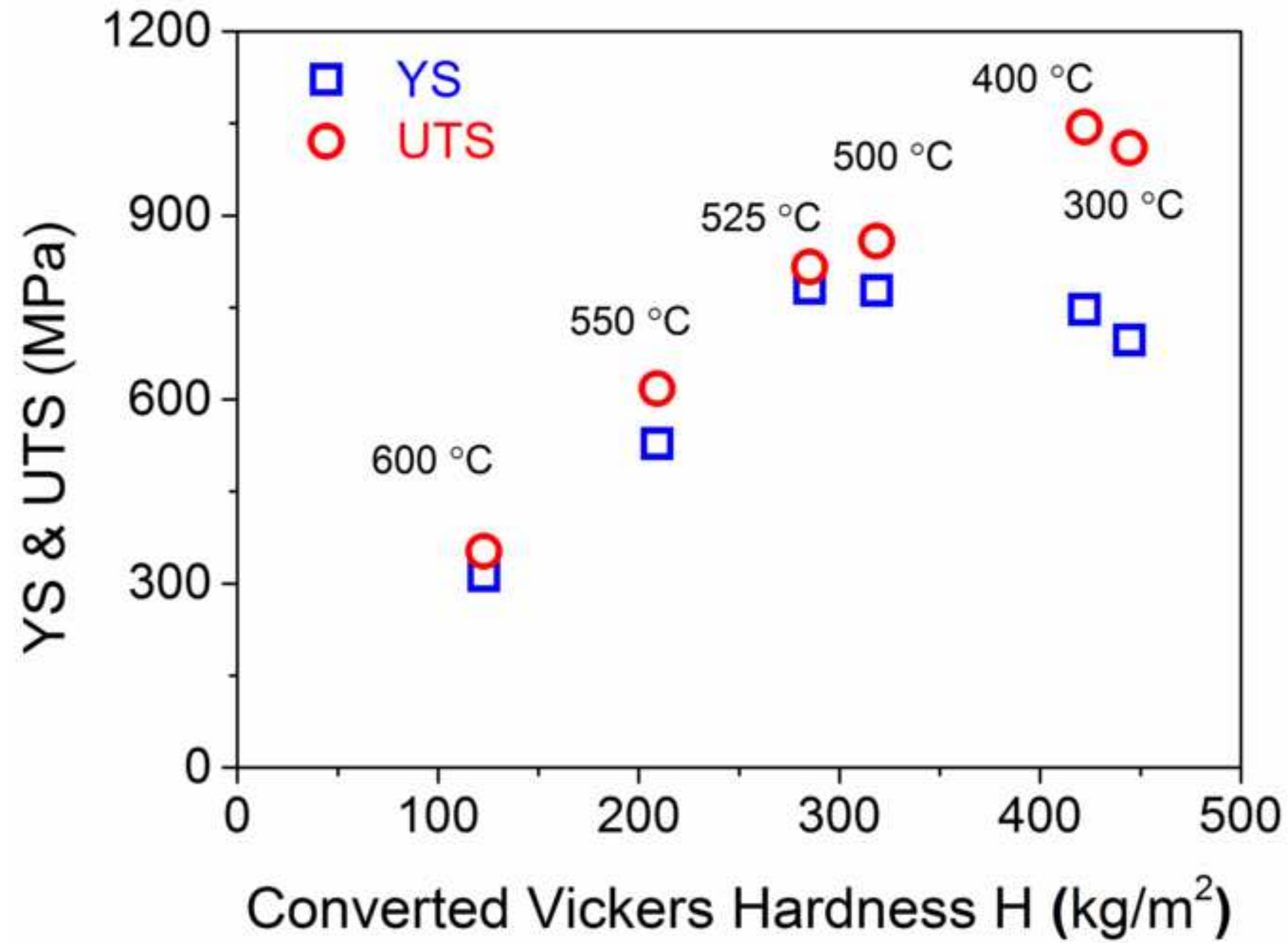


“A high temperature mechanical study on PH 13-8 Mo maraging steel." by Huang et al.

\section{Table I}

Table I: Chemical composition of PH 13-8 Mo maraging steel.

\begin{tabular}{ccccccc}
\hline \hline & $\mathrm{C}$ & $\mathrm{Al}$ & $\mathrm{Cr}$ & $\mathrm{Mo}$ & $\mathrm{Ni}$ & $\mathrm{Fe}$ \\
\hline Wt.\% & 0.03 & 1.10 & 12.70 & 2.20 & 8.20 & Bal. \\
\hline At.\% & 0.14 & 2.26 & 13.52 & 1.27 & 7.73 & Bal. \\
\hline
\end{tabular}


“A high temperature mechanical study on PH 13-8 Mo maraging steel.” by Huang et al.

\section{$\underline{\text { Table II }}$}

Table II: Test parameters and mechanical properties obtained by HT nanoindentation for the temperature cycles T1, T2 and T3.

\begin{tabular}{|c|c|c|c|c|c|c|}
\hline & \multicolumn{3}{|c|}{ Test parameters } & \multicolumn{3}{|c|}{ Mechanical properties } \\
\hline & Temperature & $\begin{array}{l}\text { Max. } \\
\text { Load }\end{array}$ & $\begin{array}{c}\text { Loading/ } \\
\text { Unloading } \\
\text { Rate }\end{array}$ & Hardness & $m$ & $V^{*}$ \\
\hline & $\left({ }^{\circ} \mathrm{C}\right)$ & $(\mathrm{mN})$ & $(\mathrm{mN} / \mathrm{s})$ & $(\mathrm{GPa})$ & & $\left(b^{3}\right)$ \\
\hline \multirow{6}{*}{$\mathrm{T} 1$} & RT & 20 & $2 / 2$ & $4.17 \pm 0.12$ & --- & --- \\
\hline & 300 & 20 & $2 / 2$ & $4.65 \pm 0.31$ & $0.09 \pm 0.08$ & $1.8 \pm 1.8$ \\
\hline & 400 & 15 & $1.5 / 1.5$ & $4.41 \pm 0.26$ & $0.12 \pm 0.06$ & \\
\hline & 500 & 13 & $1.3 / 1.3$ & $3.33 \pm 0.13$ & $0.32 \pm 0.05$ & $4.4 \pm 0.6$ \\
\hline & 525 & 15 & $1.5 / 1.5$ & $2.98 \pm 0.1$ & $0.30 \pm 0.05$ & $5.7 \pm 0.6$ \\
\hline & $\mathrm{RT}_{\text {after cooling }}$ & 20 & $2 / 2$ & $6.24 \pm 0.33$ & --- & --- \\
\hline \multirow{6}{*}{$\mathrm{T} 2$} & $\mathrm{RT}$ & 35 & $3.5 / 3.5$ & $6.24 \pm 0.33$ & & --- \\
\hline & 300 & 25 & $2.5 / 2.5$ & $5.28 \pm 0.35$ & $0.06 \pm 0.04$ & $2.9 \pm 2.9$ \\
\hline & 400 & 25 & $2.5 / 2.5$ & $4.69 \pm 0.69$ & $0.12 \pm 0.08$ & $3.2 \pm 2.5$ \\
\hline & 500 & 20 & $2 / 2$ & $3.37 \pm 0.42$ & $0.30 \pm 0.01$ & $4.2 \pm 0.5$ \\
\hline & 600 & 10 & $1 / 1$ & $1.29 \pm 0.39$ & $0.26 \pm 0.05$ & $20.1 \pm 6.8$ \\
\hline & $\mathrm{RT}_{\text {after cooling }}$ & 35 & $3.5 / 3.5$ & $4.81 \pm 0.06$ & --- & --- \\
\hline \multirow{7}{*}{$\mathrm{T} 3$} & $\mathrm{RT}$ & 20 & $2 / 2$ & $3.85 \pm 0.28$ & & \\
\hline & 300 & 20 & $2 / 2$ & $4.21 \pm 0.19$ & $0.04 \pm 0.02$ & $3.8 \pm 3.6$ \\
\hline & 350 & 20 & $2 / 2$ & $4.19 \pm 0.37$ & $0.03 \pm 0.01$ & $0.01 \pm 0.0$ \\
\hline & 450 & 20 & $2 / 2$ & $3.98 \pm 0.26$ & $0.26 \pm 0.01$ & $4.0 \pm 0.8$ \\
\hline & 550 & 20 & $2 / 2$ & $2.19 \pm 0.09$ & $0.35 \pm 0.03$ & $8.2 \pm 1.2$ \\
\hline & 625 & 20 & $2.5 / 6.7$ & $1.18 \pm 0.15$ & $0.31 \pm 0.04$ & $21.9 \pm 1.2$ \\
\hline & $\mathrm{RT}_{\text {after cooling }}$ & 20 & $2 / 2$ & $4.64 \pm 0.37$ & --- & --- \\
\hline
\end{tabular}


"A high temperature mechanical study on PH 13-8 Mo maraging steel." by Huang et al.

\section{Table III}

Table III. Test parameters and yield stress (YS), ultimate tensile strength (UTS) and total elongation (TE) obtained by HT tensile tests.

\begin{tabular}{ccccc}
\hline \multirow{2}{*}{ Tests parameters } & \multicolumn{3}{c}{ Mechanical properties } \\
\hline Temperature & Holding time & YS & UTS & TE \\
& & & & $(\%)$ \\
$\left({ }^{\circ} \mathrm{C}\right)$ & $(\mathrm{min})$ & $(\mathrm{MPa})$ & $(\mathrm{MPa})$ & \\
& & & & $5.7 \pm 0.9$ \\
100 & 30 & $751 \pm 36$ & $995 \pm 13$ & $8.8 \pm 3.4$ \\
200 & 30 & $673 \pm 21$ & $992 \pm 20$ & $4.9 \pm 0.3$ \\
300 & 30 & $696 \pm 26$ & $1010 \pm 38$ & $4.1 \pm 1.0$ \\
400 & 30 & $746 \pm 20$ & $1043 \pm 7$ & $14.1 \pm 2.1$ \\
500 & 30 & $758 \pm 36$ & $929 \pm 94$ & 10.2 \\
525 & 240 & 777 & 858 & $26.3 \pm 6.1$ \\
550 & 240 & 780 & 816 & $31.2 \pm 16.2$ \\
600 & 30 & $708 \pm 29$ & $679 \pm 24$ & $33.2 \pm 23.2$ \\
700 & 240 & $527 \pm 47$ & $617 \pm 103$ & $353 \pm 2.6$ \\
\hline
\end{tabular}

